\title{
Aeroelastic Model and Analysis of an Active Camber Morphing Wing
}

\author{
Jiaying Zhang ${ }^{1}$, Alexander D. Shaw ${ }^{1}$, Chen Wang ${ }^{1}$, Huaiyuan Gu${ }^{1}$, Mohammadreza \\ Amoozgar $^{2}$, Michael I. Friswell ${ }^{1}$ and Benjamin K.S. Woods ${ }^{3}$ \\ ${ }^{1}$ College of Engineering, Swansea University, Swansea SA2 8PP, United Kingdom \\ ${ }^{2}$ School of Computing and Engineering, University of Huddersfield, HD1 3DH, United Kingdom \\ ${ }^{3}$ Department of Aerospace Engineering, University of Bristol, Bristol BS8 1TR, United Kingdom \\ E-mail: jiaying.zhang@swansea.ac.uk
}

\begin{abstract}
Morphing aircraft structures usually introduce greater compliance into aerodynamic sections, and therefore will affect the aeroelasticity with the potential risk of increased flutter. A low-fidelity model of an active camber morphing wing and its aeroelastic model are developed in order to investigate the potential critical speed by exploiting its chord-wise dimension and flexibility. Such a model may be used for conceptual design, where low fidelity models are used to explore and optimise a wide range of configurations. The morphing camber concept is implemented using a continuous representation of a two-segment structure with a rigid segment and a deformable part. The aeroelastic model is developed based on both steady and unsteady aerodynamic models, so that different parameters can be easily modified to examine changes in the flutter solutions. Of particular interest are the ratio of the morphing segment length to the chord, and its relative stiffness, as such morphing camber is potential operated using the deformable part as a flap. By comparing the results of the quasi-steady and unsteady aerodynamic models, it is shown that the quasi-steady aerodynamic model gives a more conservative prediction of the flutter speed. In addition, responses in phase space are simulated to show the fundamental aeroelastic behaviour of the morphing camber wing. It is also shown that the active compliant segment can be used to stabilise the morphing aircraft by using feedback control. This paper provides a system-level insight through mathematical modelling, parameter analysis and feedback control into dynamics applications of morphing camber.
\end{abstract}

Keywords: morphing camber, rigid-flexible structure, flutter, feedback control 


\section{Nomenclature:}

\begin{tabular}{|c|c|c|c|}
\hline$\alpha$ & pitch angle & $\omega_{i}$ & $\begin{array}{l}i \text { th natural frequency of the morphing } \\
\text { segment }\end{array}$ \\
\hline$\zeta_{1}, \zeta_{2}$ & proportional damping constants & $\rho$ & density of morphing camber spine \\
\hline$b$ & semi-length of the rigid segment & $t_{h}$ & thickness of morphing camber spine \\
\hline$c$ & chord & $w$ & $\begin{array}{l}\text { transverse displacement of the } \\
\text { morphing segment }\end{array}$ \\
\hline$h$ & plunge displacement at elastic axis & $x$ & $\begin{array}{l}\text { position on the morphing segment } \\
\text { along the chordline }\end{array}$ \\
\hline$I_{r}$ & moment of inertia of the rigid segment & $l$ & length of the morphing camber spine \\
\hline$k_{\theta}$ & pitch stiffness of the rigid segment & $A$ & $\begin{array}{l}\text { cross sectional area of the morphing } \\
\text { segment }\end{array}$ \\
\hline$k_{h}$ & plunge stiffness of the rigid segment & $E$ & $\begin{array}{l}\text { Young's modulus of the morphing } \\
\text { camber spine }\end{array}$ \\
\hline$m_{1}$ & mass of rigid part & $T_{s}$ & $\begin{array}{l}\text { kinetic energy of the morphing } \\
\text { segment }\end{array}$ \\
\hline$r$ & $\begin{array}{l}\text { distance between elastic axis and rigid } \\
\text { segment trailing edge }\end{array}$ & $U_{s}$ & strain energy of the morphing segment \\
\hline$T_{r}$ & kinetic energy of the rigid segment & $\rho_{\infty}$ & air density \\
\hline$U_{r}$ & strain energy of the rigid segment & $U_{\infty}$ & flow speed \\
\hline$x_{c g}$ & $\begin{array}{l}\text { distance between elastic axis and } \\
\text { centre of gravity }\end{array}$ & $\mathrm{CM}$ & centre of mass of the rigid segment \\
\hline$x_{f}$ & $\begin{array}{l}\text { distance between elastic axis and } \\
\text { leading edge }\end{array}$ & EA & elastic axis \\
\hline$\beta$ & $\begin{array}{l}\text { frequency parameter of the morphing } \\
\text { segment }\end{array}$ & $P_{c}$ & circulatory pressure \\
\hline$\theta$ & slope of the morphing segment & $P_{n c}$ & non-circulatory pressure \\
\hline$\xi$ & $\begin{array}{l}\text { generalised displacements of the } \\
\text { morphing segment }\end{array}$ & $\mathrm{RE}$ & rigid segment trail edge \\
\hline
\end{tabular}




\section{Introduction}

Advances in the development of smart actuators and compliant structures have led to widespread interest in morphing wings [1]. The aircraft system can therefore integrate morphing concepts to allow shape changes of the structure, and thus adapt its aerodynamic properties to suit changing mission requirements. Morphing aircraft concepts are showing the potential to significantly reduce the mass and energy consumption, and improve flight performance, compared to traditional aircraft structures, and hence they are receiving widespread interest across the aerospace industry [1-8]. Traditional actuators, such as electromechanical servos, can be used as linear and rotary actuators, combined with mechanisms to provide a powerful tool for morphing [9]. Smart materials have been used as actuators to control wing panels [10,11], spanwise deflection [12] and trailing-edge flaps [13,14]. Many morphing wing structures are designed as compliant mechanisms to allow the desired deformation [15-21]. A morphing leading-edge model was designed as a monolithic aluminium internal compliant mechanism to provide droop-nose morphing [18]. A compliant spar concept was presented and modelled to change the wingspan, which can enhance the operational performance and provide the roll control for a unmanned aerial vehicle (UAV) [19]. However, a potential consequence of wing morphing is that the wing structures become more flexible, and hence the dynamic properties of the wing and aerodynamic loads are affected. Therefore, the aeroelastic problems of morphing wings, as an interaction between the configuration-varying aerodynamics and the morphing structure, require investigation when dramatically changing their configurations during flight. To meet this challenge, effective theoretical formulations and computational methods are developed in this paper to model the coupled structural and aerodynamic behaviour of an active camber morphing wing.

Significant research on the aeroelasticity of conventional wings already exists, but recently there has been increasing interest specifically in morphing wings. A real-time hybrid aeroelastic simulation platform for flexible wings and an efficient scheme to obtain the aerodynamic sensitivities for highly flexible aircraft have been studied [22,23]. A folding wing structure has been modelled theoretically using linear plate theory and its aeroelastic stability was studied by using a three-dimensional time domain vortex lattice aerodynamic model [24]. A further continuum model with exact solutions was developed to show the fundamental physics of folding-wing configurations [25,26]. The corresponding experiments were designed and the wind tunnel test results were compared with the predictions of a computational model for three folding wing configurations. The dynamical characteristics of a flexible membrane wing have been investigated and validated by using computational fluid dynamics simulations and experiments in a wind tunnel [27]. Moreover, a wide range of research in the aeroelastic analysis of 2D morphing aerofoil have been validated using analytical aerodynamic models and CFD techniques which is extremely reliable and enables high-fidelity structural analysis. The dynamic properties of most compliant structures have been investigated in axial flow, such as a cantilevered plate 
[28]. Similar to the cantilevered plate, interconnected beams in a fluid flow have been studied to show that the hinge position can affect the critical flutter speed [29]. A series of flexible aerofoils have been investigated by considering them as a beam structure in axial flow. Rayleigh's beam equation was used to model a flexible aerofoil, which describes the aerofoil's chordwise dynamics [30]. The effect of chordwise flexibility of a compliant aerofoil was investigated numerically to show the dynamical stability [31,32]. An actuated two-dimensional membrane aerofoil has been investigated experimentally and numerically and suggests that membrane flexibility might decrease the drag and delay the stall. In [33], a 2D aerofoil section fitted with a flap-like deformable trailing edge actuator was investigated to determine flutter and divergence instability limits. The in-plane motion and deformation of the $2 \mathrm{D}$ structure were described by three degrees of freedom, namely heave translation, pitch rotation and flap deflection, and the results show that the undeflected flap aerofoil section has a higher stability limit than the rigid aerofoil.

A wide range of research into the aeroelastic characteristics of 2D aerofoils has been conducted using both analytical aerodynamic models and CFD techniques, which are extremely reliable and enable highfidelity structural analysis. High-fidelity analysis is limited to realistic and detailed models that implies high costs. The primary aim of this paper is to investigate a quick and easy way to access the theoretical formulation of an active camber morphing wing and its aeroelastic model. A promising active camber morphing concept is considered, known as the Fish Bone Active Camber (FishBAC) [34], which uses a biologically inspired internal bending beam and elastomeric matrix composite as the skin surface, as shown in Fig. 1. The benefit of active camber is that it is capable of large camber changes and morphs the camber of an aerofoil smoothly and continuously, so that the deformable part of the aerofoil will function as a flap. Hence, ensuring the stability of the deformable part is essential in such morphing camber applications. In addition, morphing camber has been studied by strategically locating negative stiffness devices to tailor the required deployment forces and moments for passive energy balancing [35]. Therefore, the ratio of the morphing segment length to the chord and relative stiffness tailored by negative stiffness of the deformable part are the most important to check and test intuitively. In other words, the active compliant segment can be used to stabilise the morphing aircraft while ensuring the compliant segment is also stable. Furthermore, most of the works on flexible aerofoils have considered the whole aerofoil as a compliant structure [30-32,36-38] or attached a compliant structure to the trailing edge as an additional part $[39,40]$, which cannot accurately represent the aeroelastic model of FishBAC. For this study, the active camber morphing wing is considered as a low fidelity model with two chordwise segments; a non-morphing D-spar towards the leading edge and a biologically inspired compliant structure towards the trailing edge. The assembled aerofoil is then used to create a dynamic model of that can be used to provide insight into the system level dynamics, including the prediction of flutter. The model may also be used to design and assess feedback control schemes to improve the 
ddynamic performance. This analysis is different from those previously reported, since few papers in the literature considers dynamic models of morphing concepts.

The low fidelity model is firstly considered as a rigid-flexible structure and Hamilton's principle is used to develop the dynamic model based on flexible multi-body dynamics theory [41-44]. A traditional linear structural model is developed by neglecting the structural nonlinearity and using orthogonal structural mode shapes as a basis for the deformation of the flexible part.
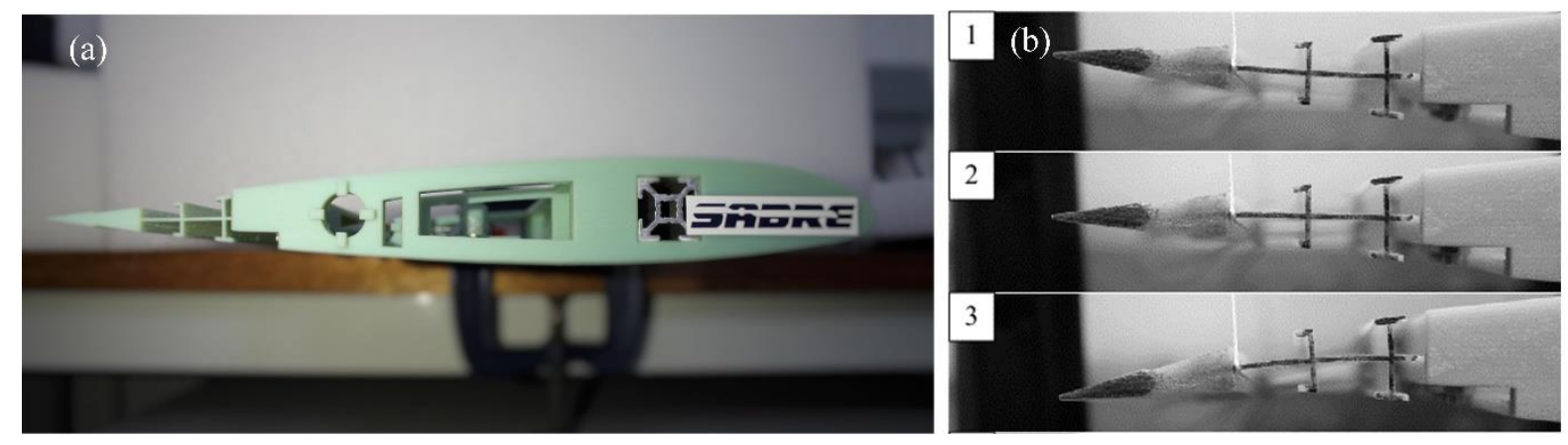

Figure 1. Active camber morphing wing. (a) Morphing wing in the undeformed state. (b) Morphing wing in the deformed state [45].

The aeroelastic model based on the active camber morphing wing is then investigated by again dividing the aerofoil into a rigid segment and a morphing segment, respectively. Two linear aerodynamic models are considered: quasi-steady and fully unsteady. The aerodynamic load provided by the rigid segment is considered as a transitional 2 degree-of-freedom (DOF) stall model and the aerodynamic load provided by the morphing segment is simulated as a compliant structure in an axial flow. Moreover, by considering the varying unsteady aerodynamic load characteristics with frequency, a model reduction method based on singular value decomposition has been used to analyse the unsteady aeroelastic problem [46].

Based on the theoretical formulation and its aeroelastic model, the eigenvalue evolution is then analysed to show unstable behaviour of the morphing wing with increasing free stream velocity. Two known cases from the literature [34,37] are used for validation, a classic 2 DOF model and a panel model. Then, since the goal of the FishBAC concept is to change the flight condition by operating the compliant segment, the compliant segment should enable a more stable system than a rigid airfoil, since control may be provided by the FishBAC acting a flap. Therefore, the relative length and stiffness of the morphing segment is then varied to change the flutter solutions, which can help to understand the fundamental aeroelastic behaviour of the active morphing camber wing. The results of the developed structural model coupled with the quasi-steady and unsteady aerodynamic models are compared to show the different dynamic behaviour and aeroelastic response of the active camber morphing wing. In addition, free vibration analysis are investigated to show an immediate understanding of how the 
morphing camber behaves under different dynamic conditions. Finally, recognising that the compliant segment can function as a flap to change the aerodynamic load, a feedback control method is used to stabilise the morphing aircraft by using the compliant segment. The results show that the compliant camber wing can be stabilised by using the compliant segment.

\section{Development of the Structural Model}

The morphing camber model shown in Fig. 2 consists of two chord segments; the front segment is a non-morphing D spar and the rear segment is a biologically inspired compliant structure. The rear segment is clamped to the non-morphing D spar that can be considered rigid. The rotation of the tendon spooling pulley causes the tendons to morph the trailing edge upward or downward and produces a continuous change of camber.

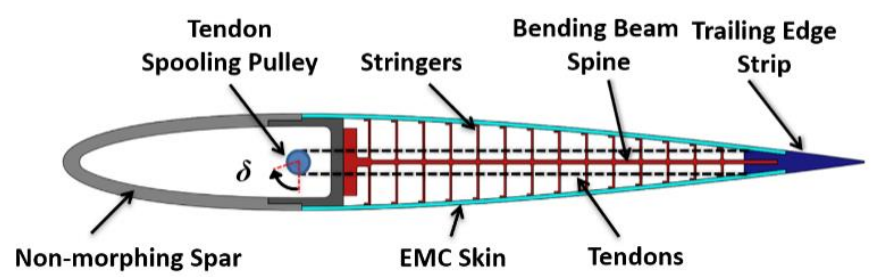

Figure 2. Schematic of the morphing camber model [34].

The current derivation considers two camber segments of equal span, as shown in Fig.3. The front segment is a non-morphing D spar based on a symmetric, uncambered NACA 0012 aerofoil, which has been extensively analysed for its two-dimensional aeroelastic behaviour. It is assumed that the wing has support stiffness $k_{h}$ and $k_{\alpha}$ in the vertical (heave) and rotation (pitch) directions, respectively. Elastic beam theory is used to describe the dynamic behaviour of the camber segments. CM is the centre of mass of the rigid segment and EA is the elastic axis.

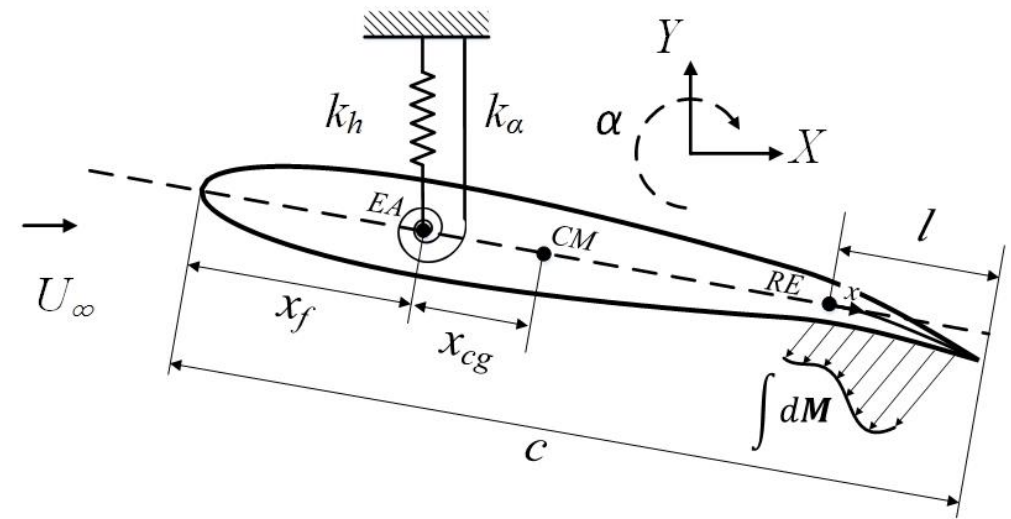

Figure 3. Aerofoil schematic defining the two segment camber. 
It is important to properly define the angle of attack $\alpha$ and the plunge distance $h$ of the EA perpendicular to the flow. The flow velocity $U_{\infty}$ is in the $X$ direction, and $h$ is positive upwards in the $Y$ direction, as shown in Fig. 3. Forces due to gravity are considered negligible and are thus excluded from the analysis.

The overall kinetic energy is obtained by considering each segment separately. The kinetic energy is calculated by integrating the product of local mass and velocity squared across the wing. The resulting expression for the kinetic energy of the rigid aerofoil, $T_{r}$, is

$$
\begin{gathered}
T_{r}=\frac{1}{2} \int \rho A(\dot{h}+\dot{\alpha} x)^{2} d x=\frac{1}{2}\left(\int \rho A \dot{h}^{2} d x+\dot{\alpha}^{2} \int \rho A x^{2} d x+2 \dot{h} \dot{\alpha} \int \rho A x d x\right) \\
=\frac{1}{2} m_{1} \dot{h}^{2}+\frac{1}{2} I_{r} \dot{\alpha}^{2}+m_{1} x_{c g} \dot{h} \dot{\alpha}
\end{gathered}
$$

where $I_{r}$ and $m_{1}$ are the moment of inertia and mass of the rigid part, respectively.

The kinetic energy due to the camber morphing part, $T_{s}$, is calculated from the velocities in the chordwise and thickness directions, which are determined with respect to a fixed coordinate system $X Y$ as

$$
\begin{gathered}
V_{1}=-\dot{\alpha} w \\
V_{2}=\dot{h}+\dot{w}+\dot{\alpha}(x+r)
\end{gathered}
$$

where $V_{1}$ is second order and may be neglected, $r$ is the distance between $E A$ and $R E$ and $x$ is coordinate of the unit mass of camber morphing part along chordline from $R E$. The transverse deformation of the morphing segment, $w$, is approximated by

$$
w(x, t)=\phi_{1} \xi_{1}+\phi_{2} \xi_{2}+\cdots=\sum_{j=1}^{n} \phi_{i} \xi_{i}
$$

where $\phi_{1}, \phi_{2}, \ldots \phi_{i}$ are the basis functions and $\xi_{1}, \xi_{2}, \ldots \xi_{i}$. are the generalised displacements. The basis functions are conveniently given by modelling the flexible section as an Euler-Bernoulli beam. The basis functions are then the mass normalised cantilever beam modes with four boundary conditions (BCs): two from the clamped end of the morphing camber, and two from the free end of the morphing camber. These BCs are given by

$$
\begin{gathered}
w(0, t)=w^{(1)}(0, t)=0 \\
w^{(2)}(l, t)=E I w^{(3)}(l, t)=0
\end{gathered}
$$

where $w^{(i)}$ denotes the $i$ th order derivative of $w$ respect to $x$, for $i=1,2,3 \ldots$.

The kinetic energy of the flexible aerofoil, $T_{s}$, is expressed as 


$$
T_{s}=\frac{1}{2} \int \rho A\left(V_{2}\right)^{2} d x=\frac{1}{2} \int_{0}^{l} \rho A\left(\dot{h}+\sum_{j=1}^{n} \phi_{i} \dot{\xi}_{i}+\dot{\alpha}(x+r)\right)^{2} d x
$$

where $\int_{0}^{l} \phi_{i} \rho A \phi_{i} d x=1$.

The kinetic energy of the whole aerofoil, $T$, can now be expressed as a fully discrete system,

$$
T=T_{s}+T_{r}=\frac{1}{2} m_{a} \dot{h}^{2}+\frac{1}{2} I_{a} \dot{\alpha}^{2}+S_{a} \dot{h} \dot{\alpha}+\frac{1}{2} \sum_{i}^{3} \dot{\xi}_{i}^{2}+\dot{h} \sum_{i}^{3} a_{i} \dot{\xi}_{i}+\dot{\alpha} \sum_{i}^{3} b_{i} \dot{\xi}_{i}
$$

where $m_{a}=m_{1}+\int_{0}^{l} \rho A d x, I_{a}=I_{r}+\int_{0}^{l} \rho A(x+r)^{2} d x, S_{a}=m_{1} x_{c g}+\int_{0}^{l} \rho A(x+r) d x, a_{i}=$ $\int_{0}^{l} \rho A \phi_{i} d x$ and $b_{i}=\int_{0}^{l} \rho A \phi_{i}(x+r) d x$.

The terms in the potential energy come from the deformation of the rigid aerofoil and from the camber morphing part with respect to the undeformed configuration. The contributions to the potential energy from the former and latter sources are denoted by $U_{r}$ and $U_{s}$, respectively. Both $U_{r}$ and $U_{s}$ follow wellknown results from the literature and total potential energy $U_{t}$ is

$$
U_{t}=U_{r}+U_{s}
$$

The contributions to the potential energy of the system, assuming three beam modes are modelled, are then

$$
\begin{gathered}
U_{r}=\frac{1}{2} K_{h} h^{2}+\frac{1}{2} K_{\alpha} \alpha^{2} \\
U_{S}=\frac{1}{2} \sum_{i}^{n} \omega_{i}^{2} \xi_{i}^{2}
\end{gathered}
$$

where $\omega_{i}$ is the $i$ th order natural frequencies of the morphing segment.

Assuming the stiffness arises from the heave and pitch springs, and the beam model of the camber, then the total potential energy is

$$
U=\frac{1}{2} k_{h} h^{2}+\frac{1}{2} k_{\alpha} \alpha^{2}+\frac{1}{2} \sum_{i}^{n} \omega_{i}^{2} \xi_{i}^{2}
$$

The applied aerodynamic force cannot be derived from a scalar potential, and hence the equations of motion are derived using the Lagrange-d'Alembert equations,

$$
\frac{d}{d t} \frac{\partial T}{\partial \dot{q}_{j}}-\frac{\partial T}{\partial q_{j}}+\frac{\partial U}{\partial q_{j}}=Q_{j}
$$


with $j=1,2, . . n$ and $q=\{h, \alpha, \xi\}, \dot{q}=\{\dot{h}, \dot{\alpha}, \dot{\xi}\}$.

Thus, the equations of motion of the morphing camber are

$$
\begin{gathered}
\ddot{\xi}_{i}+\ddot{\alpha} b_{i}+\ddot{h} a_{i}+\omega_{i}^{2} \xi_{i}=Q_{\xi_{i}} \\
I_{a} \ddot{\alpha}+S_{a} \ddot{h}+\sum_{i}^{n} b_{i} \ddot{\xi}+K_{\alpha} \alpha=Q_{\alpha} \\
m_{a} \ddot{h}+S_{a} \ddot{\alpha}+\sum_{i}^{n} a_{i} \ddot{\xi}+K_{h} h=Q_{h}
\end{gathered}
$$

where $Q_{\xi_{i}}, Q_{\alpha}$ and $Q_{h}$ denote the aerodynamic generalised forces. The dynamical equations take the form

$$
\left[\begin{array}{ccc}
\boldsymbol{I} & \boldsymbol{b}^{\boldsymbol{T}} & \boldsymbol{a}^{\boldsymbol{T}} \\
\boldsymbol{b} & I_{a} & S_{a} \\
\boldsymbol{a} & S_{a} & m_{a}
\end{array}\right]\left[\begin{array}{c}
\ddot{\boldsymbol{\xi}} \\
\ddot{\alpha} \\
\ddot{h}
\end{array}\right]+\left[\begin{array}{ccc}
\boldsymbol{K}_{\xi \xi} & 0 & 0 \\
0 & K_{\alpha} & 0 \\
0 & 0 & K_{h}
\end{array}\right]\left[\begin{array}{l}
\xi \\
\alpha \\
h
\end{array}\right]=\left[\begin{array}{l}
\boldsymbol{Q}_{\boldsymbol{w}} \\
Q_{\alpha} \\
Q_{h}
\end{array}\right]
$$

The elements of the mass and stiffness matrices are functions of the physical and geometrical properties of the system and are fully represented by $\boldsymbol{K}_{\xi \xi}=\operatorname{diag}\left(\omega_{1}^{2}, \omega_{2}^{2}, \cdots, \omega_{n}^{2}\right), \boldsymbol{Q}_{\boldsymbol{w}}=\left(Q_{\xi_{1}}, Q_{\xi_{2}}, \ldots Q_{\xi_{n}}\right), \boldsymbol{b}=$ $\left(b_{1}, b_{2}, \ldots b_{n}\right), \boldsymbol{a}=\left(a_{1}, a_{2}, \ldots a_{n}\right)$ and $\boldsymbol{I}$ is the identity matrix. The forces on the modal coordinates due to the aerodynamics are given by $Q_{\xi_{i}}=\int_{0}^{l} \phi_{i} Q_{w} d x$, and is considered in more detail next.

\section{Aerodynamic Model}

Quasi-steady and fully unsteady aerodynamic models are considered to represent aerodynamic loads. A sketch of the configuration is shown in Fig. 3; the configuration is similar to model presented in [31], except that the rigid control surface is replaced by the morphing segment.

\section{A. Quasi-Steady Aerodynamic Model}

A stall model is introduced into the quasi-steady aerodynamic approach to represent the aerodynamic loads [47]. Thus, the lift and pitching moment are given by

$$
\begin{aligned}
L=\rho_{f} \pi b^{2}(\ddot{h}- & \left.\left(x_{f}-b\right) \ddot{\alpha}\right)+\rho_{f} \pi b^{2} U_{\infty} \dot{\alpha}+\rho_{f} c \pi U_{\infty}^{2}\left(\alpha+\frac{\dot{h}}{U_{\infty}}+\left(\frac{3}{2} b-x_{f}\right) \frac{\dot{\alpha}}{U_{\infty}}\right) \\
& +L_{\text {morph }}
\end{aligned}
$$




$$
\begin{aligned}
M=\rho_{f} \pi b^{2}\left(x_{f}\right. & -b)\left(\ddot{h}-\left(x_{f}-b\right) \ddot{\alpha}\right)-\frac{\rho_{f} \pi b^{4}}{8} \ddot{\alpha}-\left(\frac{3}{2} b-x_{f}\right) \rho \pi b^{2} U_{\infty} \dot{\alpha} \\
& +\rho_{f} e c^{2} \pi U_{\infty}^{2}\left(\alpha+\frac{\dot{h}}{U_{\infty}}+\left(\frac{3}{2} b-x_{f}\right) \frac{\dot{\alpha}}{U_{\infty}}\right)-\frac{1}{2} \rho_{f} b^{3} \pi U_{\infty} \dot{\alpha}+M_{\text {morph }}
\end{aligned}
$$

where $\rho_{f}$ is density of air, $b$ is the semi-length of rigid segment, $S$ is the relevant reference area and $U_{\infty}$ is the flow speed. Furthermore, Fig. 3 shows that the morphing segment provides additional aerodynamic load, i.e. lift and pitching moment, $L_{\text {morph }}$ and $M_{\text {morph }}$, in Eqs. (15). By convention, the aerodynamic load provided by the morphing segment is simulated here as a cantilever beam in axial flow and only considering the non-circulatory pressure, i.e. $\Delta P=P_{n c}$. Then, the corresponding aerodynamic load $L_{\text {morph }}$ and $M_{\text {morph }}$ are determined as

$$
\begin{gathered}
L_{\text {morph }}=\int_{0}^{l} \Delta P(x, t) \cos \theta d x \\
M_{\text {morph }}=\int_{0}^{l} \Delta P(x, t) \cos \theta(x+r) d x
\end{gathered}
$$

where $\theta$ is the slope of the morphing segment, i.e. $\partial w / \partial x$, and it varies along the morphing part. Recalling Eqs. (14), the corresponding generalized force of the $i$ th mode can now be determined as

$$
Q_{u_{2}}^{i}=\int_{0}^{l} \Delta P(x, t) \phi_{i}(x) d x=\int_{0}^{l} P_{n c}(x, t) \phi_{i}(x) \cos \theta d x
$$

The small deflections of the morphing segment create a transverse velocity and thus a velocity potential. Thus, based on aerofoil theory $[29,48]$, the non-circulatory pressure according to the linearised Bernoulli equation is

$$
P_{n c}(x, t)=-2 \rho_{f} \frac{\partial^{2} w}{\partial t^{2}} \sqrt{x(l-x)}+\frac{\rho_{f} U_{\infty}(2 x-l)}{\sqrt{x(l-x)}}\left(\frac{\partial w}{\partial t}+U_{\infty} \frac{\partial w}{\partial x}\right)
$$

$t$ is time. The full aeroelastic equations of motion are of the form

$$
\left(\boldsymbol{A}+2 \rho_{f} \boldsymbol{B}\right) \ddot{\boldsymbol{q}}+\left(\boldsymbol{C}+\rho_{f} U_{\infty} \boldsymbol{D}\right) \dot{\boldsymbol{q}}+\left(\boldsymbol{E}+\rho_{f} U_{\infty}^{2} \boldsymbol{F}\right) \boldsymbol{q}=0
$$

where $\boldsymbol{A}, \boldsymbol{B}, \boldsymbol{C}, \boldsymbol{D}, \boldsymbol{E}, \boldsymbol{F}$ are the structural inertia, aerodynamic inertia, structural damping, aerodynamic damping, structural stiffness, and aerodynamic stiffness matrices respectively, and $\boldsymbol{q}$ are generalised coordinates. Although general viscous damping could be used, in the examples, proportional structural damping is assumed, which expresses the damping matrix as a linear combination of the mass and stiffness matrices. Structural damping is notoriously difficult to model, and proportional damping is a simple approach used to introduce structural damping to the important modes contributing to flutter. Thus,

$$
\boldsymbol{C}=\zeta_{1} \boldsymbol{M}+\zeta_{2} \boldsymbol{K}
$$


where $\zeta_{1}, \zeta_{2}$ are real scalars.

\section{B. Unsteady Aerodynamic Model}

The pressure difference, according to Theodorsen, is divided into circulatory pressure $\left(P_{c}\right)$ and noncirculatory pressure $\left(P_{n c}\right)[29]$. Hence,

$$
\Delta P=P_{n c}+P_{c}
$$

The small deflections of the morphing segment create a transverse velocity and a velocity potential. Thus, based on aerofoil theory $[48,49]$, the circulatory pressure is created due to vortex shedding at the trailing edge of the morphing segment. According to Kelvin's theorem, vorticity has to be conserved in an inviscid flow for a given topology. Therefore, to conserve the total vorticity, if there is a vorticity distribution at the wake of the morphing segment, it should be balanced by a bound vorticity distribution in the morphing segment with opposite strength. This creates a circulatory velocity potential whose finite variation at the trailing edge is governed by the Kutta-Zhukovskii condition [49]. Thus, the circulatory pressure is given by

$$
P_{c}=-\frac{\rho_{f} U_{\infty}}{\sqrt{x(l-x)}}\left(\frac{\partial w}{\partial t}+U_{\infty} \frac{\partial w}{\partial x}\right)[l(2 C(k)-1)+2 x(1-C(k))]
$$

where $C(k)$ is the Theodorsen function.

$$
C(k)=\frac{H_{1}^{(2)}(k)}{H_{1}^{(2)}(k)+i H_{0}^{(2)}(k)}
$$

where $H_{n}^{(2)}(k)$ is the $n$-th Hankel function of the second kind.

The corresponding aerodynamic loads, $L_{\text {morph }}$ and $M_{\text {morph }}$, can now be determined using Eq. (19). The unsteady aerodynamic load produced by the aerofoil can be described as [50],

$$
\begin{aligned}
& L=\rho_{f} \pi b^{2}(\ddot{h}-\left.\left(x_{f}-b\right) \ddot{\alpha}+U_{\infty} \dot{\alpha}\right)+2 \rho_{f} \pi U_{\infty}^{2} b C(k)\left(\alpha+\frac{\dot{h}}{U_{\infty}}+\left(\frac{3}{2} b-x_{f}\right) \frac{\dot{\alpha}}{U_{\infty}}\right) \\
&+L_{\text {morph }} \\
& M=\rho_{f} \pi b^{2}\left(x_{f}-b\right)\left(\ddot{h}-\left(x_{f}-b\right) \ddot{\alpha}\right)-\frac{\rho_{f} \pi b^{4}}{8} \ddot{\alpha}-\rho_{f} \pi b^{2} U_{\infty}\left(\frac{3}{2} b-x_{f}\right) \dot{\alpha} \\
& \quad+4 \rho_{f} e b^{2} \pi U_{\infty}^{2} C(k)\left(\alpha+\frac{\dot{h}}{U_{\infty}}+\left(\frac{3}{2} b-x_{f}\right) \frac{\dot{\alpha}}{U_{\infty}}\right)+M_{\text {morph }}
\end{aligned}
$$

where $e=x_{f} /(2 b)-1 / 4$.

Then, the full aeroelastic equations of motion are of the form 


$$
M_{t} \ddot{U}+C_{t} \dot{U}+K_{t} U=0
$$

where here the mass, damping and stiffness matrices combine the aerodynamic and structural contributions, and $\boldsymbol{U}$ are generalised coordinates,

$$
\boldsymbol{U}=\{\boldsymbol{q}, \boldsymbol{v}\}
$$

where $\boldsymbol{v}$ are the additional aerodynamic DOFs, as defined in the Appendix. The aerodynamic stiffness matrices are also presented in the Appendix.

\section{Numerical validation and results}

The test case considered for numerical validation is the Fish Bone Active Camber presented by Woods et al. [34,51]. The properties of the morphing wing are listed in Table 1 and these parameters are used in the following numerical simulation.

\begin{tabular}{|c|c|c|}
\hline Parameter & Value & Units \\
\hline \multicolumn{3}{|l|}{ Rigid camber segment } \\
\hline Chord, $c$ & 0.254 & $\mathrm{~m}$ \\
\hline Mass of rigid part, $m_{1}$ & 3.3843 & $\mathrm{~kg} / \mathrm{m}$ \\
\hline Centre of gravity, $x_{c g}$ & 0.0264 & $\mathrm{~m}$ \\
\hline Elastic axis, $x_{0}$ & 0.0635 & $\mathrm{~m}$ \\
\hline Moment of inertia, $I_{r}$ & 0.0135 & $\mathrm{~kg} \mathrm{~m}^{2}$ \\
\hline Proportional damping constant, $\zeta_{1}$ & 0.012 & $1 / \mathrm{s}$ \\
\hline Proportional damping constant, $\zeta_{2}$ & 0.0015 & $\mathrm{~s}$ \\
\hline Pitch stiffness, $k_{\theta}$ & 94.37 & $\mathrm{Nm} / \mathrm{rad}$ \\
\hline Plunge stiffness, $k_{h}$ & 2844.4 & $\mathrm{~N} / \mathrm{m}$ \\
\hline \multicolumn{3}{|l|}{ Morphing camber segment } \\
\hline Length, $l$ & $0.25 c$ & $\mathrm{~m}$ \\
\hline Young's modulus, $E$ & $72 \mathrm{e} 9$ & $\mathrm{~Pa}$ \\
\hline Thickness of morphing camber spine, $t_{h}$ & $1 e-3$ & $\mathrm{~m}$ \\
\hline Density, $\rho$ & 2700 & $\mathrm{~kg} / \mathrm{m}^{3}$ \\
\hline \multicolumn{3}{|l|}{ Air parameters } \\
\hline Density, $\rho_{\infty}$ & 1.225 & $\mathrm{~kg} / \mathrm{m}^{3}$ \\
\hline
\end{tabular}

Table 1. Aerodynamic and structural properties of the morphing aerofoil.

\section{A. Eigenvalue evolution}

The section presents the resulting aeroelastic eigenvalues and first three natural frequency of the morphing segment is considered. Most aeroelastic systems show unstable behaviour with increasing flow velocity. In this section, the stability condition of the aerofoil system is examined using a linear eigenvalue analysis. The homogenous form of the system of Eq. (14) may be linearized by neglecting the nonlinear excitations terms. The resulting linear homogenous system of equations is then easily transferred to state-space form as 


$$
\dot{\boldsymbol{\eta}}=\boldsymbol{H} \boldsymbol{\eta}
$$

where $\boldsymbol{\eta}$ is the state vector defined by

$$
\boldsymbol{\eta}=\left\{\frac{\boldsymbol{q}}{\dot{\boldsymbol{q}}}\right\}
$$

$\boldsymbol{H}$ is the constant dynamic system matrix

$$
\boldsymbol{H}=\left[\begin{array}{cc}
{[0]_{(2+n) \times(2+n)}} & \boldsymbol{I}_{(2+n) \times(2+n)} \\
-\boldsymbol{M}^{-\mathbf{1}} \boldsymbol{K} & {[0]_{(2+n) \times(2+n)}}
\end{array}\right]
$$

and $n$ is the selected number of mode shapes of $\boldsymbol{\Phi}, \boldsymbol{K}$ is the stiffness matrices and $\boldsymbol{I}$ is the identity matrix. For linear dynamic systems, the response of Eq. (27) is asymptotically exponentially stable in the sense of Lyapunov if and only if all of the eigenvalues of $\boldsymbol{H}$ have negative real parts. The root locus plot of these eigenvalues can easily characterize the stability condition of the linear system.
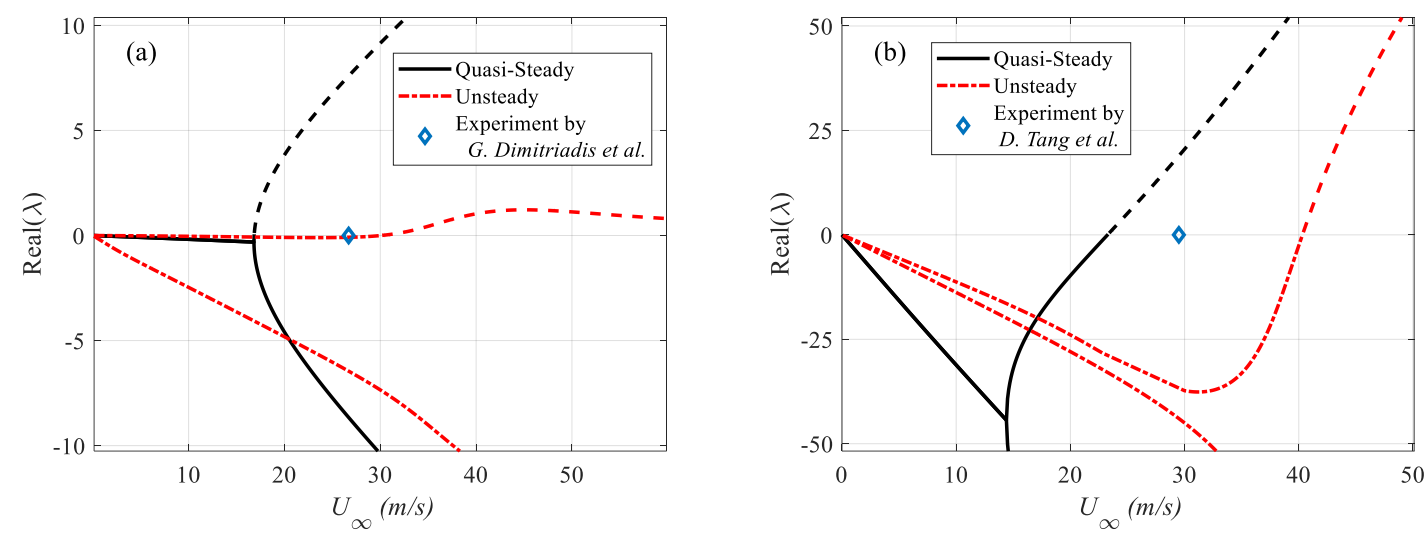

Figure 4. The real parts of the eigenvalue $\lambda$ with respect to $U_{\infty}$ (solid or dash-dotted is stable, dashed line indicates a shift from stable to is unstable). The threshold value of $U_{\infty}$ is identified as the flutter velocity. (a) 2 DOF model with pitch and plunge [52] (b) a two dimensional panel model [49].

Given that the current aeroelastic model for a rigid-flexible camber configuration is relatively complicated, the results for two cases from the literature [49,52], a classic 2 DOF model and a panel model, are given in Fig. 4 and compared with established results from the literature. Figure 4 shows the results of a 2 DOF system with pitch and plunge and a two dimensional panel model using the same system parameters as those from the literature. The maximum airspeeds for a stable response for the pitch and plunge model are $18 \mathrm{~m} / \mathrm{s}$ (Quasi-steady) and 30m/s (Unsteady), which was observed at $26.7 \mathrm{~m} / \mathrm{s}$ from the experiment, as shown in Fig. 4(a). Figure 4(b) shows that the critical flutter speeds of the two dimensional panel are $23 \mathrm{~m} / \mathrm{s}$ (Quasi-steady) and $40 \mathrm{~m} / \mathrm{s}$ (Unsteady), compared to $29.5 \mathrm{~m} / \mathrm{s}$ in the literature. While the agreement between the proposed model and experiment isn't perfect, it does show 
roughly similar results and can give valuable predicts. Therefore, it is confidence to use this analysis for initial considerations of aeroelastic model of a camber morphing wing.

We now consider the aeroelastic response of the compliant morphing structure. There is a scaling of the critical flutter velocity $[29,48]$ given by

$$
U_{c} \sim \sqrt{\frac{E t_{h}^{3}}{\rho_{f} l^{3}}}
$$

If the thickness of the panel increases, then the critical velocity will also increase. By considering different freestream velocities $U_{\infty}$, the critical flutter velocity can be determined from the unsteady and quasi-steady models. The importance of the aerodynamic model used can be appreciated by the dramatic differences of the flutter speeds. In addition, the structural natural frequencies of the compliant structure, modelled as a uniform beam, can be obtained as

$$
\omega_{i}=\sqrt{\frac{E I}{\rho A l^{4}}} \beta_{i} l^{4}
$$

Therefore, it is apparent that a shorter chord compliant structure can be effective in delaying flutter. Based on the solution verification of the two baseline models, the eigenvalue evolution method is used to analyse the critical velocity of the morphing camber model under different aerodynamic loads using Eq. (14). 

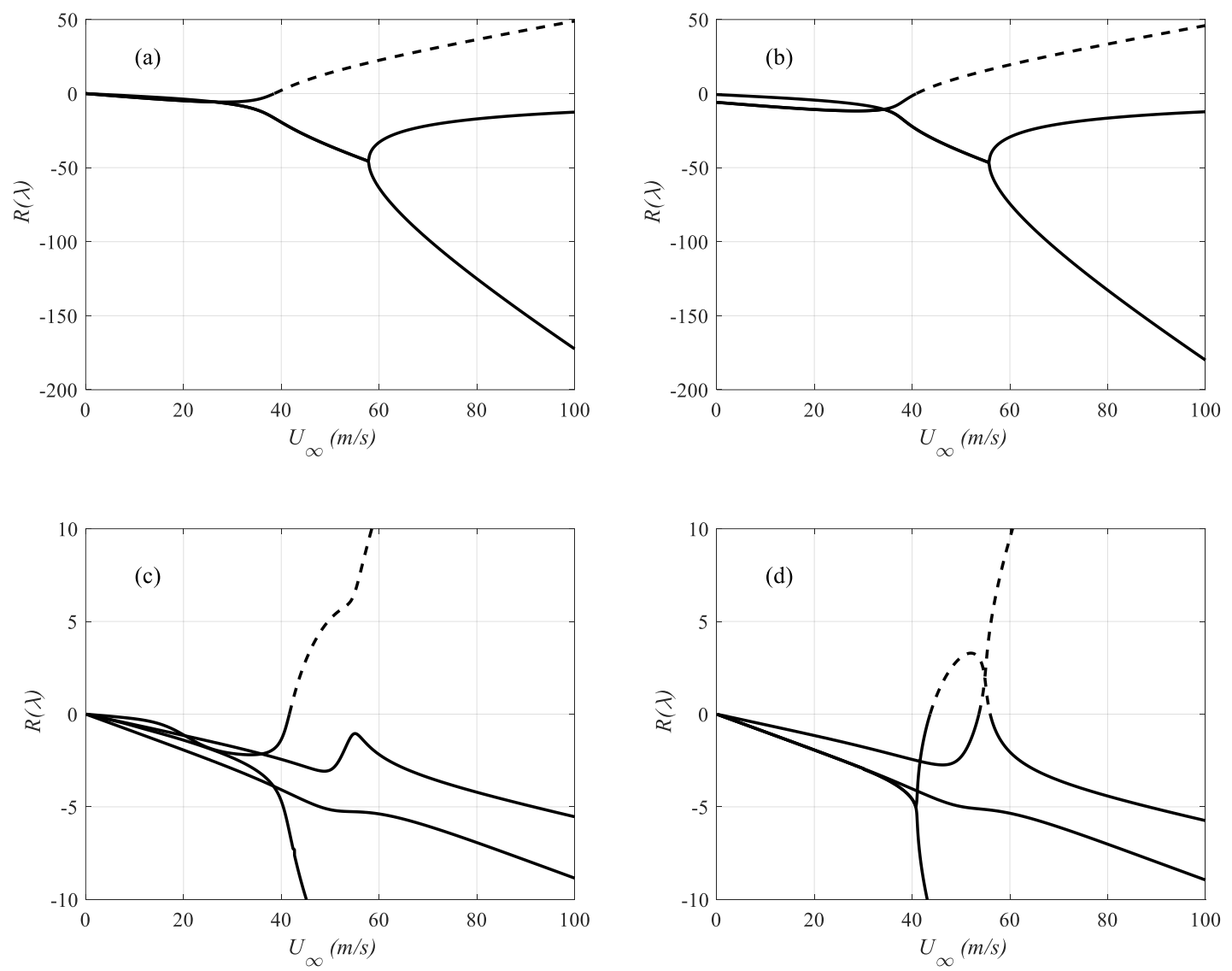

Figure 5. The real parts of the eigenvalue $\lambda$ with respect to $U_{\infty}$ for the active morphing camber model (solid is stable, dashed is unstable). The threshold value that occurs of $U_{\infty}$ is identified as the flutter velocity. Morphing camber model (a) without structural damping under quasi-steady aerodynamic load (b) with structural damping under quasi-steady aerodynamic load (c) without structural damping under unsteady aerodynamic load (d) with structural damping under unsteady aerodynamic load.

Figure 5 shows the evolution of the real parts of the eigenvalue $\lambda$ with respect to $U_{\infty}$ for the active morphing camber model. The two aerodynamic models are considered as loads for the structure model with or without structural damping. The different aerodynamic models give similar critical flutter speeds and the unsteady aerodynamic model always delays flutter. However, the dynamics with the unsteady model are significantly more complex. Moreover, structural damping tends to delay flutter as the damping helps to dissipate energy and hence is stabilising. 

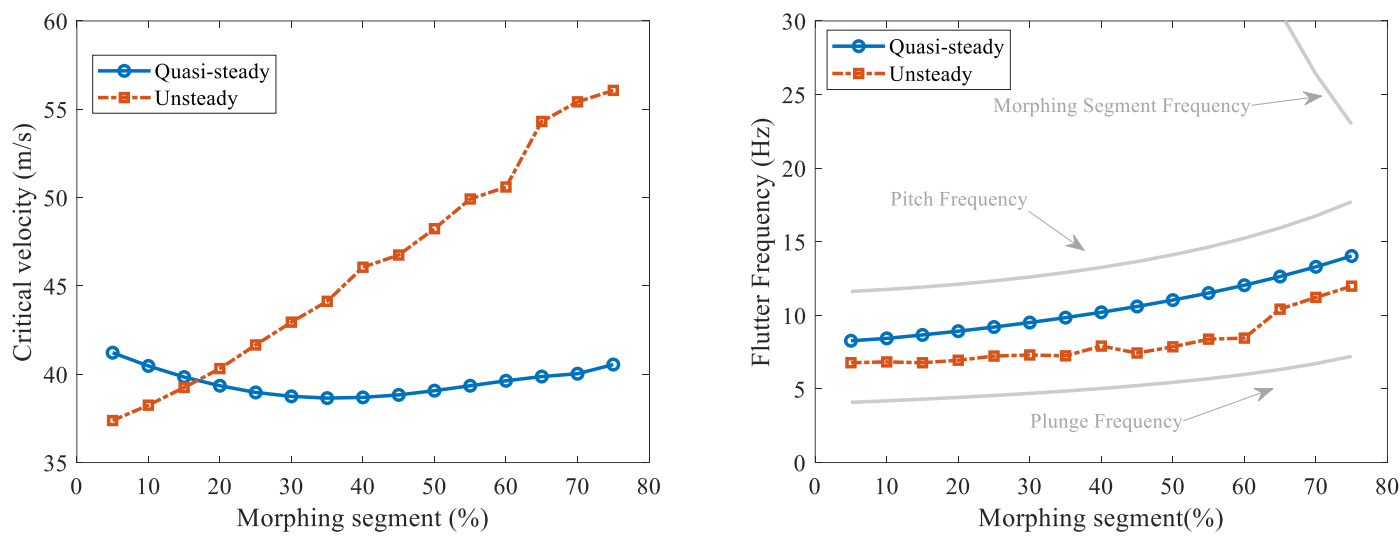

Figure 6. Flutter speed and frequency for different ratios of morphing segment (\%) (a) flutter speed (b) flutter frequency. The grey lines are the natural frequencies of the structural model.

Figure 6 illustrates the effects of the ratio of morphing segment (\%) on the flutter speed and frequency. The ratio of morphing segment means the proportion between the morphing segment to the chord of the aerofoil. Note that the flutter speed is not a monotonic function of the ratio of morphing segment and indeed the quasi-steady value has a minimum. The ratio of morphing segment affects both the structural and aerodynamic models. Moreover, the effect of the quasi-steady aerodynamic theory is to reduce the variation in flutter speed. It is also seen that the quasi-steady aerodynamic theory gives an overly conservative prediction of flutter speed relative to the prediction of the fully unsteady aerodynamic theory. In addition, the critical velocity in unsteady aerodynamic model increases. The reason is that for a fixed chord length, increasing the morphing segment can reduce the inertia in the pitch and plunge motion and therefore the corresponding frequency increases. Figure $6(\mathrm{~b})$ shows the flutter frequency for different ratios of morphing segment for the unsteady aerodynamic model. The flutter frequency increases with increasing morphing segment ratio and lies between the pitch and plunge natural frequency. 

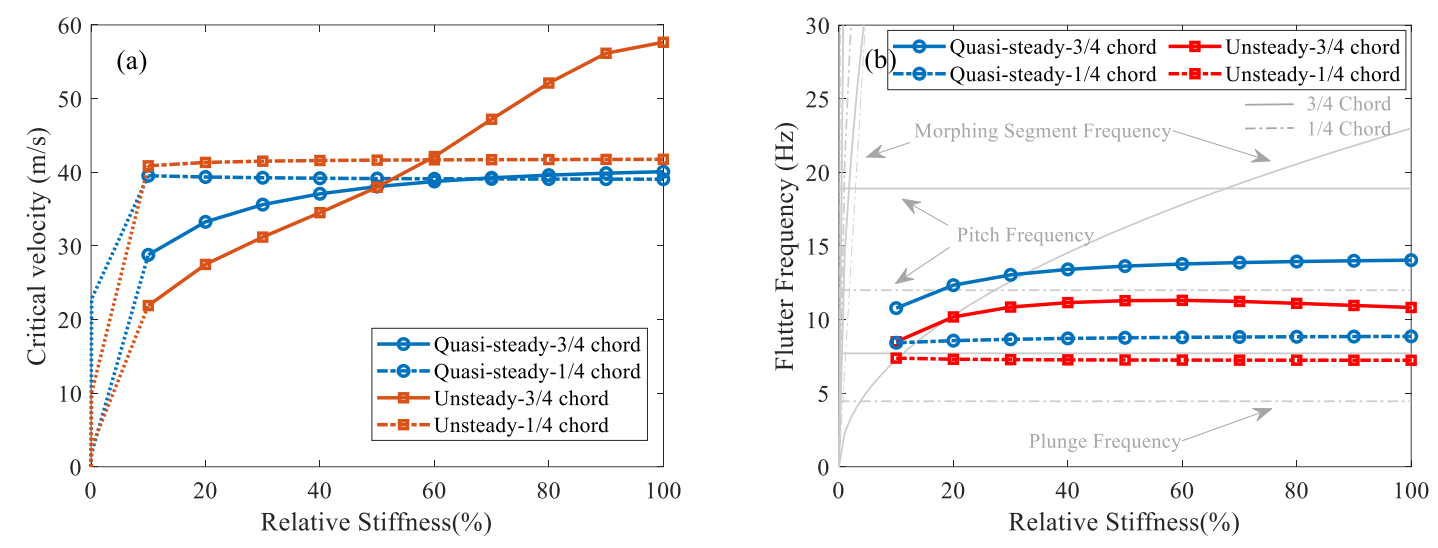

Figure 7. Flutter speed and frequency for different stiffnesses of the morphing segment (\%). (a) Flutter speed (b) Flutter frequency. The grey lines are the natural frequency of the structural model. Solid lines indicate the $3 / 4$ chord morphing ( $75 \%$ ratio of morphing segment) and dash-dot lines indicate $1 / 4$ chord morphing ( $25 \%$ ratio of morphing segment).

Figure 7(a) illustrates the effects of different stiffnesses of the morphing segment (\%) on the flutter speed. The stiffness of the morphing segment is changed by scaling its Young modulus. As the stiffness of the morphing segment affects the structural model, it produces some interesting changes in the aeroelasticity. When the stiffness of the morphing segment reduced to $60 \%$, local flutter of the morphing segment will occur for the 3/4 chord morphing case. Figure 7(b) shows the flutter frequency for the different stiffness cases. There is a change in the flutter modes in the $3 / 4$ chord morphing segment case, as the first mode frequency of morphing segment is between the natural frequencies of pitch (12.3 $\mathrm{Hz})$ and plunge $(4.5 \mathrm{~Hz})$, which is close to the first natural frequency of the morphing segment. The corresponding operational deflection shapes for the motion are shown in Fig. 8(b), which represents a large response of the morphing segment. When the key natural frequencies are brought closer together by the variation in stiffness of the morphing segment, the flutter speed becomes lower and vice versa. However, there is not an analogous phenomenon in the 1/4 chord morphing segment case, even if the stiffness is less than $10 \%$ of the baseline. Thus the length of the morphing segment is more sensitive than its stiffness, which confirms the results of Eq. (31). Moreover, there is a different critical velocity for $3 / 4$ chord morphing segment case than other cases, and the $100 \%$ stiffness case is the same as the $75 \%$ ratio of morphing segment result shown in Fig. 6. It is known that the length of the morphing segment can reduce the inertia in the pitch and plunge motion and therefore the corresponding frequency is increased. Furthermore, when keeping the same morphing segment length, decreasing the stiffness of morphing segment can reduce its rigidity and the corresponding frequency is decreased. By comparing Fig. 8(b) and Fig. 8(d) shows that the reduced rigidity of morphing segment can lead to corresponding increased motion of the morphing segment. Since the motion of morphing segment is coupled with pitch and plunge by recalling eq. (14), therefore the critical velocity will also change. The 
results in Figs. 6 and 7 provide a parametric study that is useful in the design of the compliant segment for morphing camber.
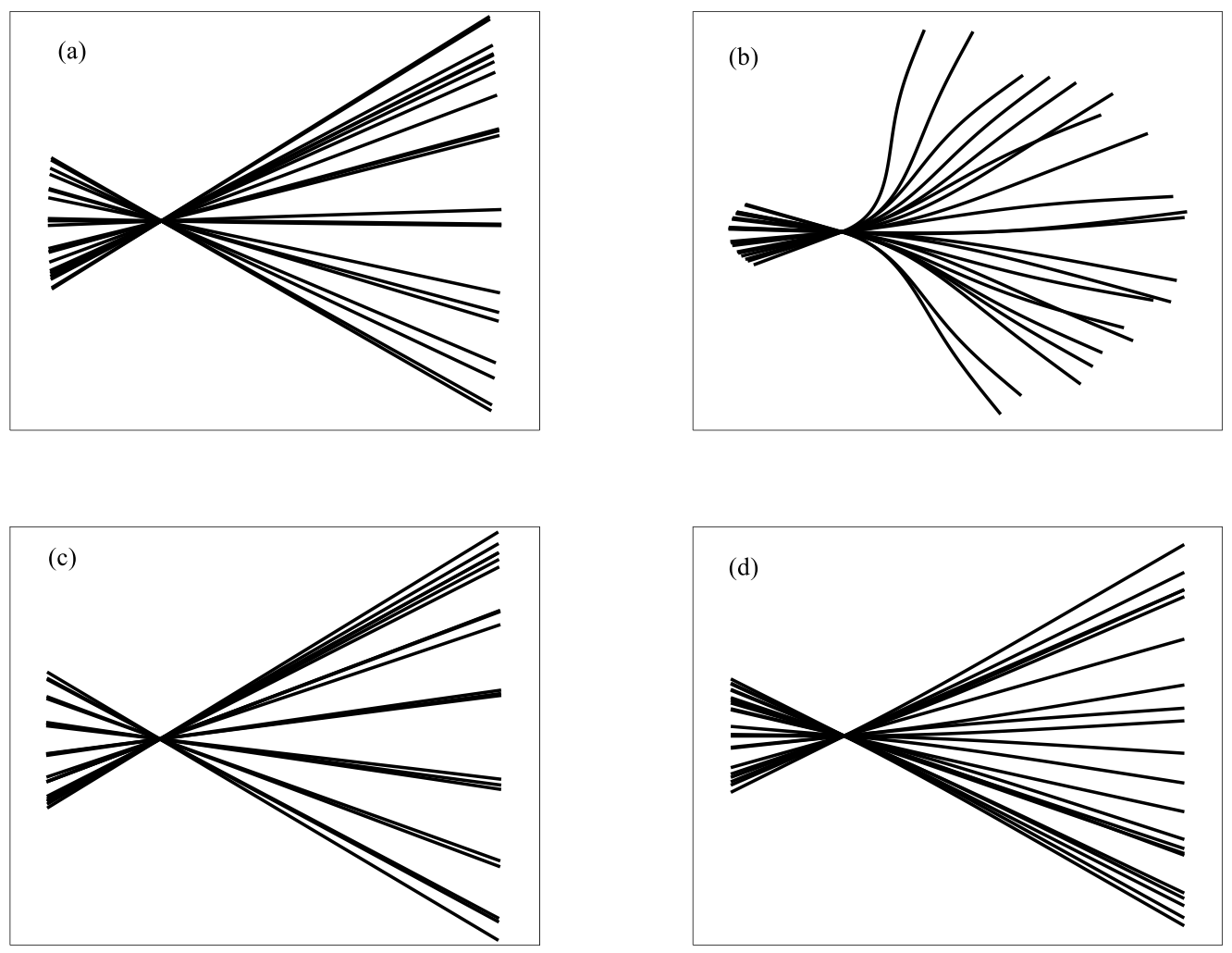

Figure 8. Mode shapes at the flutter speed. (a) $1 / 4$ chord morphing segment with $10 \%$ relative stiffness (b) $3 / 4$ chord morphing segment with $10 \%$ relative stiffness (c) $1 / 4$ chord morphing segment with $100 \%$ relative stiffness (d) $3 / 4$ chord morphing segment with $100 \%$ relative stiffness.

Figure 8 shows the corresponding mode shapes of the solution for different cases, and highlights that the characteristics of the morphing segment can influence the stability of the aerofoil. When the morphing segment becomes more compliant, the high response of morphing part can lead to instability of the whole aerofoil. Moreover, the flutter frequency in Fig. 7(b) gives similar results that the structural natural frequency of the morphing segment (i.e. its stiffness) can determine the flutter frequency if the rigidity of morphing segment is small.

\section{B. Free vibration analysis}

The system parameters to be used in the following numerical investigations are given in Table 1. To investigate the accuracy of the present analytical solutions, the 2 DOF aerofoil system with characteristics given in Table 1 is considered first. The initial conditions for the system are assumed to be a small perturbation of $\alpha=5^{\circ}$, resulting in the time response shown in Figs. 9. By comparing the 
response of the morphing camber model (Morphing) and the 2 DOF aerofoil system (Rigid), the morphing segment is shown to cause a distinct delay without significant differences in the amplitude of the response. In addition, the response of the morphing camber model (Morphing) is in good qualitative agreement with the behaviour observed for the $2 \mathrm{DOF}$ aerofoil system.
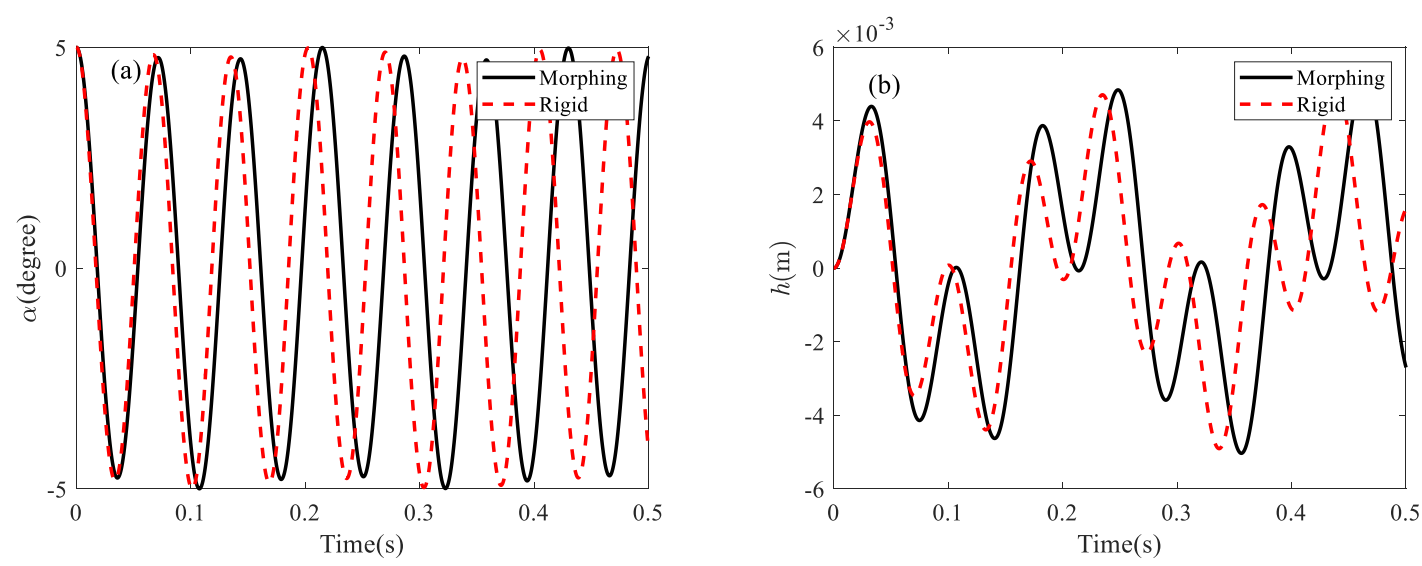

Figure 9. Free vibration response. The solid line indicates the morphing camber model (Morphing) and the dashed line indicates the baseline 2 DOF aerofoil system (Rigid) with pitch and plunge. (a) Pitch response (b)

Plunge response.

Figure 10 shows the time responses for two different ratios of morphing segment of the morphing camber model (Morphing), in which M1 is the 1/4 chord morphing segment and M2 is the 3/4 chord morphing segment. Different ratios of morphing segment can change the response of the system, especially the camber tip response, as shown in Fig. 10(c). Moreover, the response in pitch shown in Fig. 10(a) shows that there is a certain reduction in amplitude for the longer morphing segment, as the energy is mainly applied to the vibration of the morphing segment.
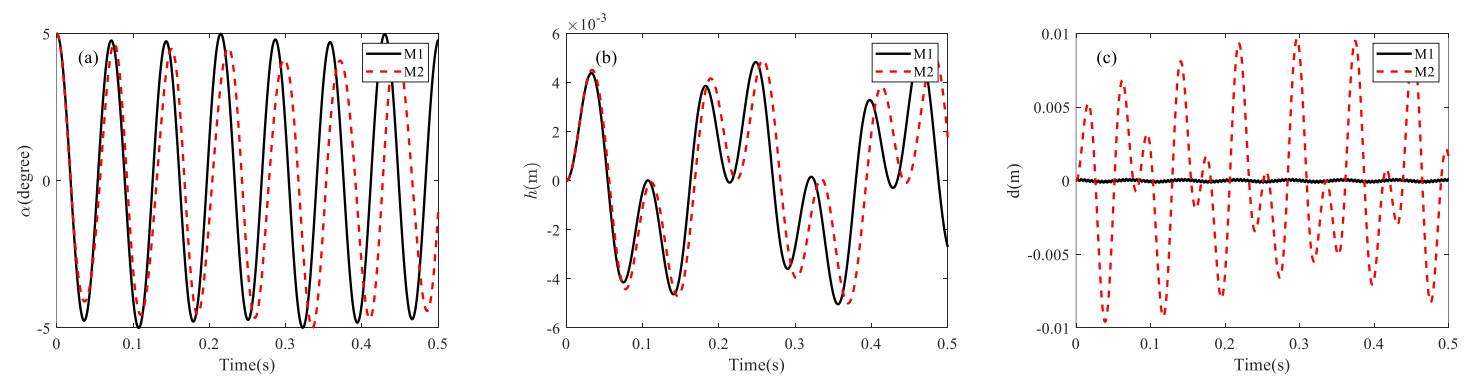

Figure 10. Free vibration response of two morphing camber model, M1 is 1/4 chord morphing segment and M2 is 3/4 chord morphing segment. (a) Pitch response (b) Plunge response (c) Camber tip response.

\section{Aeroelastic response}

Depending on the air speed of the free stream, there are three different types of behaviour that exist in the dynamic response of aeroelastic systems: (1) the response will converge to the equilibrium states when the air speed is less than the flutter speed (2) the system will maintain self-sustained response 
when the air speed is equal to or slightly above the flutter speed, or (3) the response will diverge and the system will move into an oscillatory manner with increasing amplitude when the air speeds significant exceeds the critical flutter speed. Therefore, it is well known that the equations of motion of the morphing camber system just derived exhibit responses as discussed in Section 4.A. The system parameters to be used in the following numerical investigations are given in Table 1.
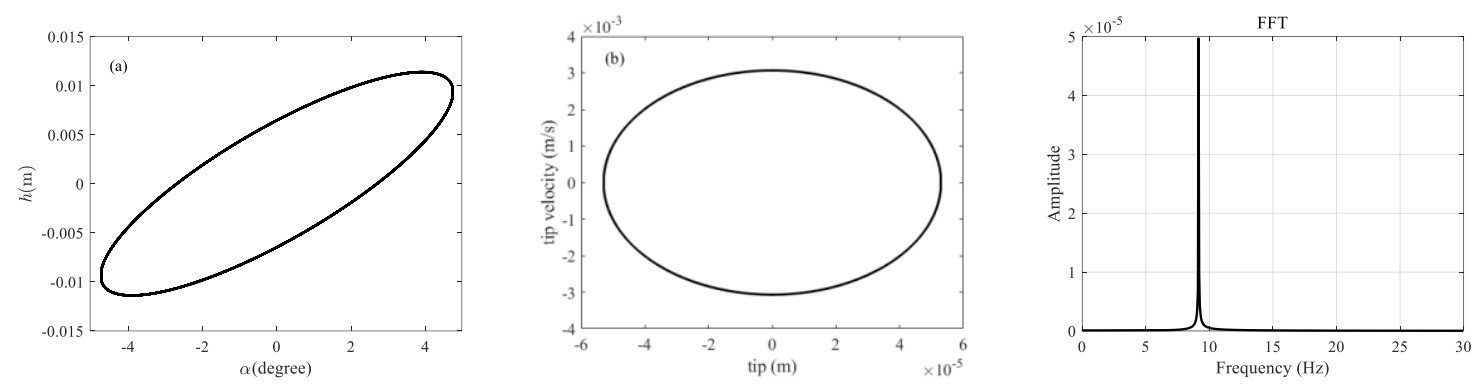

Figure 11. Phase portraits for the quasi-steady aerodynamic model at critical velocity $U_{\infty}=38.97 \mathrm{~m} / \mathrm{s}(1 / 4$ chord morphing segment). (a) Pitch-plunge (b) Camber tip phase portrait (c) FFT of camber tip displacement.

The response was first simulated for a quarter chord morphing segment with the quasi-steady aerodynamic model and the air velocity close to the flutter speed shown in Fig. 5, namely $U_{\infty}=$ $38.97 \mathrm{~m} / \mathrm{s}$. Due to geometric stiffness effects, the camber tip oscillates in a stable response in phase space, almost harmonically between $\mp 0.047 \mathrm{~mm}$, as shown in Fig. 11. The FFT plot shows that a dominant harmonic for the camber tip displacement exists with a frequency of $9 \mathrm{~Hz}$.
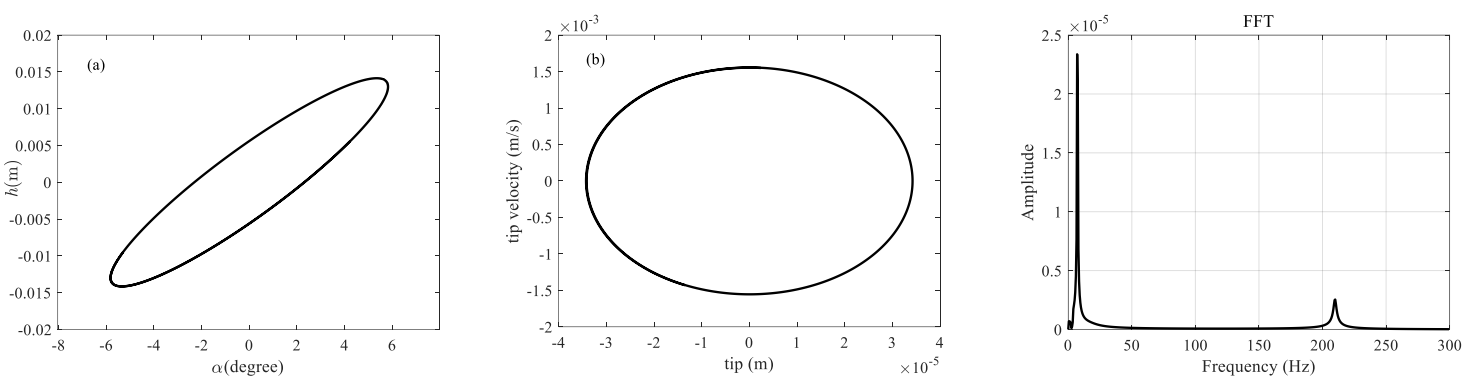

Figure 12. Phase portraits for the unsteady aerodynamic model at critical velocity $U_{\infty}=41.65 \mathrm{~m} / \mathrm{s}$ (a) Pitchplunge (1/4 chord morphing segment) (b) Camber tip phase portrait (c) FFT of camber tip displacement.

The response was then simulated for a quarter chord morphing segment with the unsteady aerodynamic model and the critical velocity $U_{\infty}=41.65 \mathrm{~m} / \mathrm{s}$, as shown in Fig. 12. The FFT plot shows that the dominant harmonic exists, which is similar to the quasi-steady aerodynamic simulation, although there is also some response at just over $200 \mathrm{~Hz}$. The responses in phase space are different for the unsteady aerodynamic model, and larger harmonic regions of the camber tip phase portrait occur at a higher critical velocity. 

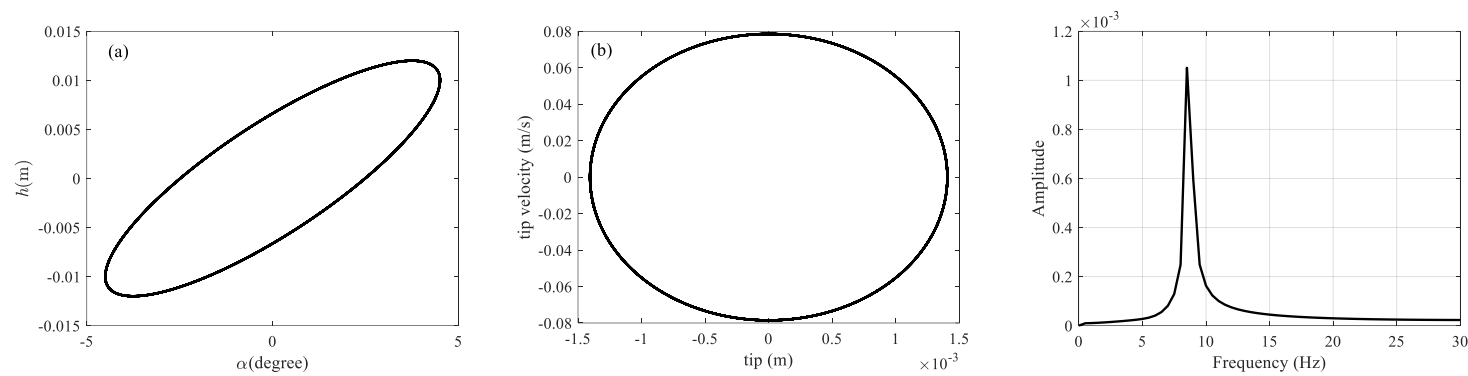

Figure 13. Phase portraits for the quasi-steady aerodynamic model at critical velocity $U_{\infty}=40.07 \mathrm{~m} / \mathrm{s}(3 / 4$ chord morphing segment). (a) Pitch-plunge (b) Camber tip phase portrait (c) FFT of camber tip displacement.

The 3/4 chord morphing segment model has also been considered under quasi-steady and unsteady aerodynamic loads, shown in Figs. 13 and 14, respectively. The responses in phase space under quasisteady aerodynamic load is similar to the responses in phase space for the 1/4 chord morphing segment model except the camber tip phase portrait has larger amplitude. The FFT plot of the camber tip displacement shows a single harmonic is dominant. Figure 14 shows that the frequency spectrum is broader for a longer morphing segment and the peak frequency of the camber tip response is changed to $11 \mathrm{~Hz}$. Compared with Fig. 13, it can be seen that the plunge and tip responses become smaller although the critical velocity is increased.
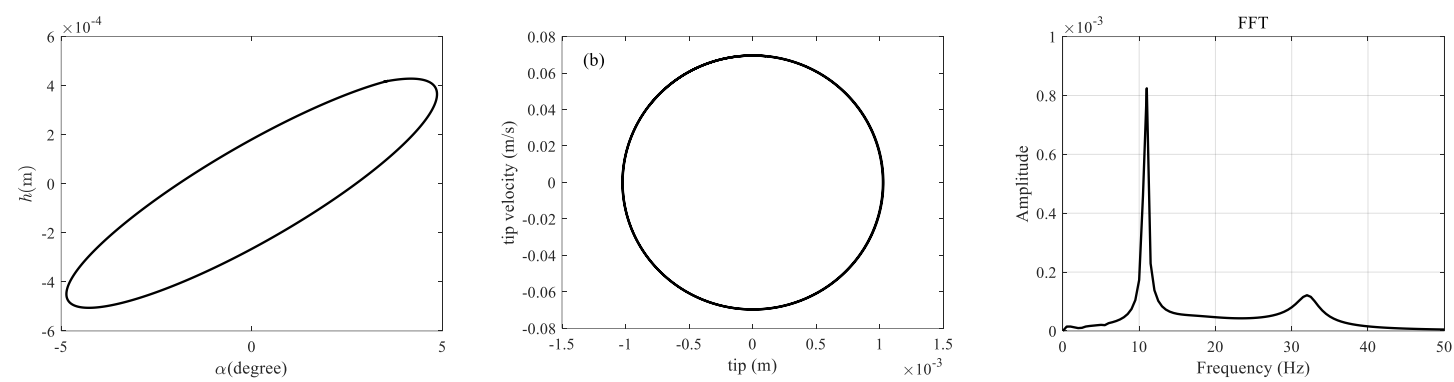

Figure 14. Phase portraits for the unsteady aerodynamic model at critical velocity $U_{\infty}=57.65 \mathrm{~m} / \mathrm{s}(3 / 4 \mathrm{chord}$ morphing segment). (a) Pitch-plunge (b) Camber tip phase portrait (c) FFT of camber tip displacement.

\section{Feedback Control of the Morphing Camber}

Based on the investigation in Section 4, if reasonable parameters of the compliant segment are chosen, the flutter of the morphing aircraft can only occur in pitch and plunge. Moreover, the concept of the morphing camber is to provide large camber changes smoothly and continuously, so the compliant segment can function as an active camber device to change the aerodynamic loads in real time. Therefore, this section presents a feedback control method to stabilise the morphing aircraft by using the compliant segment. 
Figure 15 shows schematically the forces and moments generated by the tendons due to pulley rotation, the corresponding magnitudes of which have been derived previously [34].

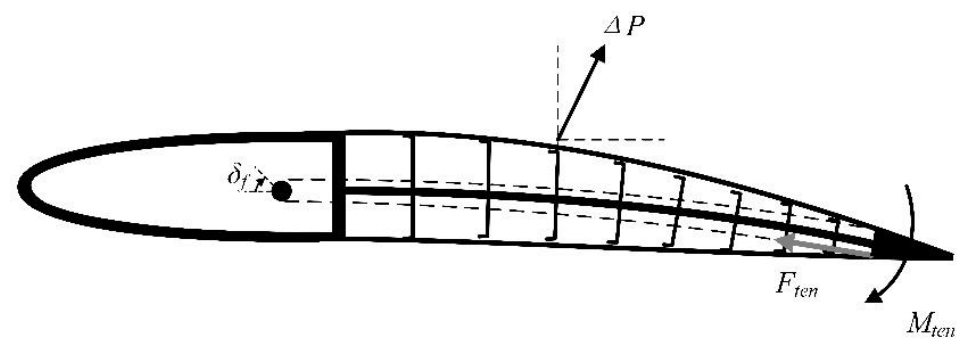

Figure 15. Schematic representation of the antagonistic tendon actuation.

The moment provided by the tendon spooling pulley can be expressed as

$$
M_{\text {ten }}=2 F_{\text {ten }} y_{\text {ten }}
$$

where $y_{t e n}$ is tendon mounting offset and $F_{t e n}$ is the force in the tendon.

The curvature of the compliant section can be integrated to give the slope as

$$
\frac{\partial w}{\partial x}=\int_{0}^{l} \frac{M_{\text {in }}}{E I} d x=\theta(x)
$$
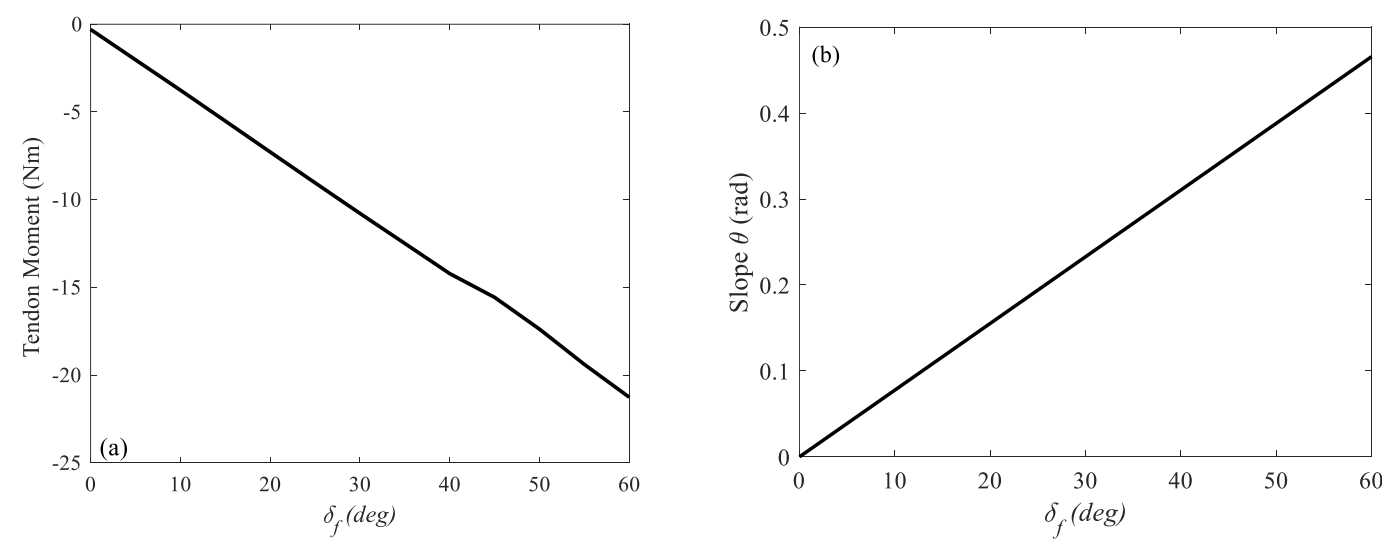

Figure 16. Structural results: (a) bending moment and (b) maximum slope $\theta$.

Figure 16(a) shows that the compliant FishBAC camber is a positive stiffness system, and the required torque is proportional to the rotation angle [53]. Figure 16(b) shows the slope produced by integration of linearised bending moment. It can be seen that the deflection of the morphing segment is small for the given bending moment and the maximum slope of the morphing camber is $0.5 \mathrm{rad}$.

The corresponding aerodynamic loads, $L_{m o r p h}$ and $M_{\text {morph }}$, can now be determined from Eq. (16) as 


$$
\begin{gathered}
L_{\text {morph }}=\int_{0}^{l} \Delta P(x, t) \cos \theta d x \\
M_{\text {morph }}=\int_{0}^{l} \Delta P(x, t) \cos \theta(x+r) d x
\end{gathered}
$$

where the quasi-steady aerodynamic model is considered here to design the control system. The noncirculatory pressure can then be used by neglecting the time-varying terms, i.e. $\frac{\partial^{2}}{\partial t^{2}}, \frac{\partial w}{\partial t}$, and the aerodynamic load provided by the morphing camber is given by

$$
\begin{gathered}
L_{\text {morph }}=\int_{0}^{l} P_{n c}(x, t) \cos \theta d x=\int_{0}^{l} \frac{\rho_{f} U_{\infty}^{2}(2 x-l)}{\sqrt{x(l-x)}} \frac{\partial w}{\partial x} \cos \left(\frac{\partial w}{\partial x}\right) d x \\
M_{\text {morph }}=\int_{0}^{l} P_{n c}(x, t) \cos \theta(x+r) d x=\int_{0}^{l} \frac{\rho_{f} U_{\infty}^{2}(2 x-l)}{\sqrt{x(l-x)}}(x+r) \frac{\partial w}{\partial x} \cos \left(\frac{\partial w}{\partial x}\right) d x
\end{gathered}
$$

Small deflections of the compliant segment are used for control and the maximum slope of the morphing camber shown in Fig. 16 is $0.5 \mathrm{rad}$. Therefore, it can be assumed that

$$
\cos \theta=\cos \left(\frac{\partial w}{\partial x}\right) \approx 1
$$

and the aerodynamic load provided by the compliant segment can be approximated by

$$
\begin{gathered}
L_{\text {morph }}=\int_{0}^{l} \frac{\rho_{f} U_{\infty}^{2}(2 x-l)}{\sqrt{x(l-x)}} \frac{\partial w}{\partial x} d x=\frac{\rho_{f} U_{\infty}^{2}}{E I} \int_{0}^{l} \frac{(2 x-l)}{\sqrt{x(l-x)}} x d x M_{i n} \\
M_{\text {morph }}=\int_{0}^{l} \frac{\rho_{f} U_{\infty}^{2}(2 x-l)}{\sqrt{x(l-x)}} \frac{\partial w}{\partial x}(x+r) d x=\frac{\rho_{f} U_{\infty}^{2}}{E I} \int_{0}^{l} \frac{(2 x-l)}{\sqrt{x(l-x)}} x(x+r) d x M_{i n}
\end{gathered}
$$

Thus, the generalised force vector is

$$
F_{\text {morph }}=\left[\begin{array}{c}
\frac{\rho_{f} U_{\infty}^{2}}{E I} \int_{0}^{l} \frac{(2 x-l)}{\sqrt{x(l-x)}} x d x \\
\frac{\rho_{f} U_{\infty}^{2}}{E I} \int_{0}^{l} \frac{(2 x-l)}{\sqrt{x(l-x)}} x(x+r) d x
\end{array}\right] u=\boldsymbol{G} u
$$

where $M_{\text {in }}=u$, and $M_{\text {in }}$ is the control input applied to the system.

Including this force into the equation for the pitch and plunge dynamics gives

$$
\frac{d}{d t}\left[\begin{array}{l}
\alpha \\
h \\
\dot{\alpha} \\
\dot{h}
\end{array}\right]=\left[\begin{array}{cc}
\mathbf{0}_{2 \times 2} & \boldsymbol{I}_{2 \times 2} \\
-\left(\boldsymbol{A}+2 \rho_{f} \boldsymbol{B}\right)^{-1}\left(\boldsymbol{E}+\rho_{f} U_{\infty}^{2} \boldsymbol{F}\right) & -\left(\boldsymbol{A}+2 \rho_{f} \boldsymbol{B}\right)^{-1}\left(\boldsymbol{C}+\rho_{f} U_{\infty} \boldsymbol{D}\right)
\end{array}\right]\left[\begin{array}{c}
\alpha \\
h \\
\dot{\alpha} \\
\dot{h}
\end{array}\right]+\boldsymbol{G} u
$$

Then, the actuation $u$ is determined using full state feedback and a proportional controller as 


$$
u=-K_{c}\left(\mathbf{x}-\mathbf{x}_{r}\right)
$$

where $x=\left[\begin{array}{llll}\alpha & h & \dot{\alpha} & \dot{h}\end{array}\right]^{T}$ is the state vector, $\mathbf{x}_{r}=\left[\begin{array}{llll}0 & 0 & 0 & 0\end{array}\right]^{T}$ is the reference position, i.e. the desired stable location, and $\boldsymbol{K}_{\boldsymbol{c}}$ is the controller gain matrix. The system is first verified and then using an LQR controller by simple chosen $Q=I$ and $R=1$ to design the controller gain matrix.
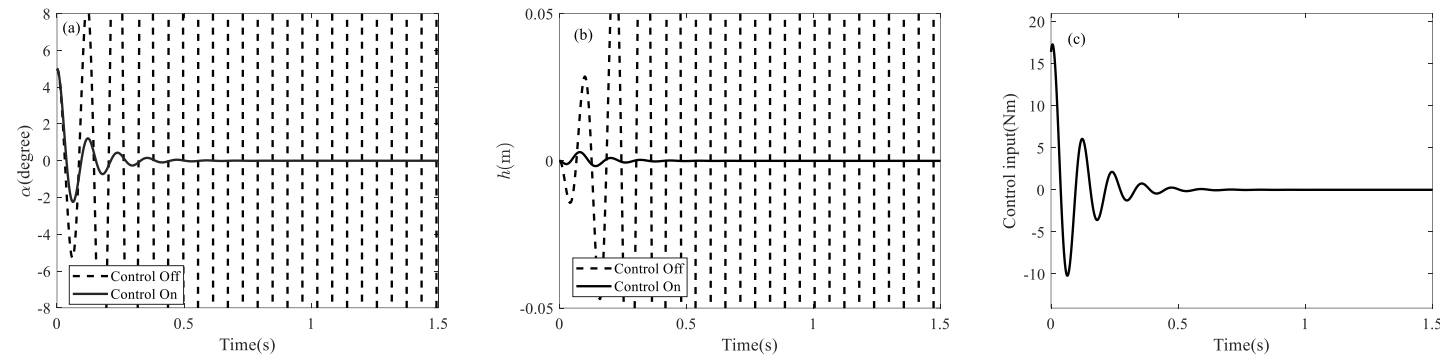

Figure 17. Example of free and controlled response at $45 \mathrm{~m} / \mathrm{s}$ (a) pitch response (b) plunge response (c) control input.
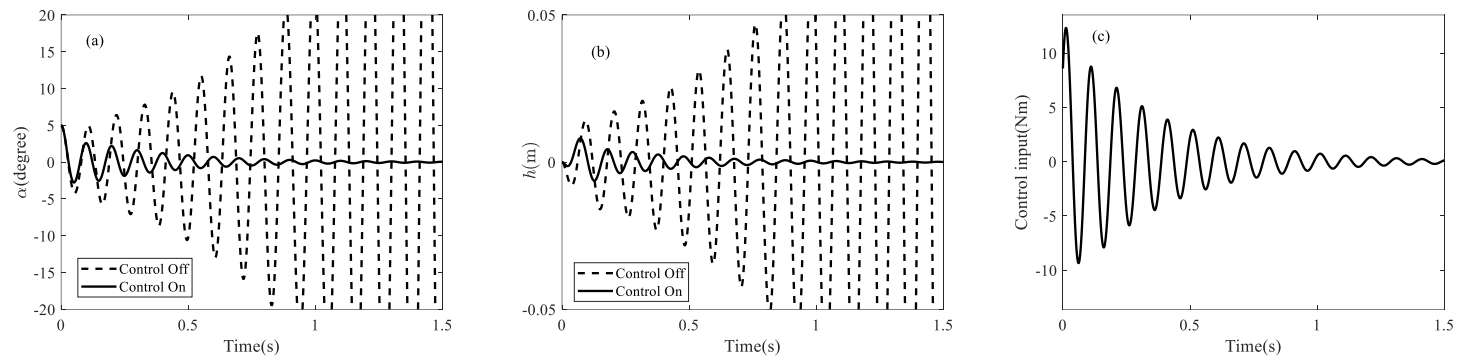

Figure 18. Example of free and controlled response at $41 \mathrm{~m} / \mathrm{s}$ (a) pitch response (b) plunge response (c) control input.
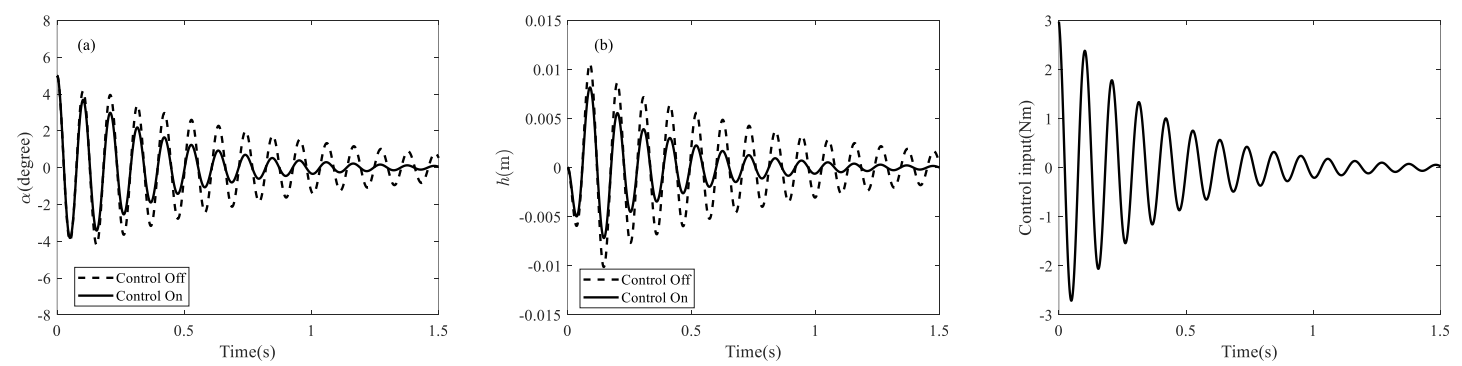

Figure 19. Example of free and controlled response at $38 \mathrm{~m} / \mathrm{s} \mathrm{(a)} \mathrm{pitch} \mathrm{response} \mathrm{(b)} \mathrm{plunge} \mathrm{response} \mathrm{(c)} \mathrm{control}$ input.

Figure 17-19 show three working scenarios using the compliant segment to stabilise the aeroelastic system. Figure 17 shows an example at the freestream velocity of $45 \mathrm{~m} / \mathrm{s}$, which exceeds the critical velocity. With the same initial conditions as before, the time response of the controlled system is shown in Figs. 17(a) and 17(b) for pitch and plunge, respectively. It can be seen that the compliant camber can be stabilised using the compliant segment. Figure 18 shows an example at the critical velocity of $41 \mathrm{~m} / \mathrm{s}$. It can be seen that the compliant camber can be stabilised using the compliant segment with a lower 
control input. However, when the air velocity is below the critical velocity, e.g. $38 \mathrm{~m} / \mathrm{s}$, the response is shown in Fig. 19. Although the system can be controlled by using the compliant segment, the contribution of the compliant segment is not significant. Therefore, the compliant segment can stabilise the morphing aircraft by selecting a reasonable controller gain matrix.

\section{Conclusions}

A theoretical formulation of an active camber morphing wing and its aeroelastic model have been developed. A continuous representation of the morphing camber model is investigated and consists of two chord segments, a non-morphing D-spar and a biologically inspired compliant structure. Therefore, the morphing wing is studied as a rigid-flexible structure; the non-morphing D-spar behaves as a traditional two-dimensional aeroelastic system with pitch and plunge and elastic beam theory is used to describe the dynamic behaviour of the camber segments. Two aerodynamic models are considered and integrated with the structural model to determine the flutter solutions. A singular value decomposition method has been used to analyse the unsteady aeroelastic problem. Different parameters of the morphing camber device can be easily modified by using the developed aeroelastic model to examine changes in the flutter solutions. Of these parameters, the ratio of the length of the morphing segment to the chord, and the stiffness of the morphing segment, are of particular interest. The results of the quasisteady and unsteady aerodynamic model are compared to show that the quasi-steady aerodynamic model gives an overly conservative prediction of the flutter speed and the unsteady aerodynamic model reduces the motion of the structure. The response of the different model has been simulated to show the fundamental aeroelastic behaviour of morphing camber, including responses in phase space. Finally, the compliant segment is used to stabilise the morphing aircraft by feedback control. The theoretical formulation and results presented in this paper can be used to provide better predictions for the dynamic behaviour of active camber morphing wings, and provides insight into the aeroelastic problem of rigidflexible structures, both in the field of morphing aircraft and in other fields. The theoretical formulation and results presented in this paper can be used to provide rapid prediction of the dynamic behaviour of active camber morphing wings.

\section{Declaration of Competing Interest}

The authors declare that they have no known competing financial interests or personal relationships that could have appeared to influence the work reported in this paper. 


\section{Acknowledgement}

This research leading to these results has received funding from the European Commission under the European Union's Horizon 2020 Framework Programme 'Shape Adaptive Blades for Rotorcraft Efficiency' grant agreement 723491.

\section{References}

[1] S. Barbarino, O. Bilgen, R.M. Ajaj, M.I. Friswell, D.J. Inman, A Review of Morphing Aircraft, J. Intell. Mater. Syst. Struct. 22 (2011) 823-877. https://doi.org/10.1177/1045389X11414084.

[2] P. Santos, J. Sousa, P. Gamboa, Variable-span wing development for improved flight performance, J. Intell. Mater. Syst. Struct. $28 \quad$ (2017) 961-978. https://doi.org/10.1177/1045389X15595719.

[3] R. Shi, W. Wan, Analysis of flight dynamics for large-scale morphing aircraft, Aircr. Eng. Aerosp. Technol. 87 (2015) 38-44. https://doi.org/10.1108/AEAT-01-2013-0004.

[4] C.S. Beaverstock, J. Fincham, M.I. Friswell, R.M. Ajaj, R. De Breuker, N. Werter, Effect of Symmetric \& Asymmetric Span Morphing on Flight Dynamics, in: AIAA Atmos. Flight Mech. Conf., American Institute of Aeronautics and Astronautics, Reston, Virginia, 2014. https://doi.org/10.2514/6.2014-0545.

[5] H. Namgoong, W.A. Crossley, A.S. Lyrintzis, Aerodynamic Optimization of a Morphing Airfoil Using Energy as an Objective, AIAA J. 45 (2007) 2113-2124. https://doi.org/10.2514/1.24355.

[6] B. Yan, P. Dai, R. Liu, M. Xing, S. Liu, Adaptive super-twisting sliding mode control of variable sweep morphing aircraft, Aerosp. Sci. Technol. $92 \quad$ (2019) 198-210. https://doi.org/10.1016/j.ast.2019.05.063.

[7] P. Dai, B. Yan, W. Huang, Y. Zhen, M. Wang, S. Liu, Design and aerodynamic performance analysis of a variable-sweep-wing morphing waverider, Aerosp. Sci. Technol. 98 (2020) 105703. https://doi.org/10.1016/j.ast.2020.105703.

[8] J.P. Eguea, G. Pereira Gouveia da Silva, F. Martini Catalano, Fuel efficiency improvement on a business jet using a camber morphing winglet concept, Aerosp. Sci. Technol. 96 (2020) 105542. https://doi.org/10.1016/j.ast.2019.105542.

[9] I. Dimino, G. Amendola, B. Di Giampaolo, G. Iannaccone, A. Lerro, Preliminary design of an actuation system for a morphing winglet, in: 2017 8th Int. Conf. Mech. Aerosp. Eng. ICMAE 2017, 2017: pp. 416-422. https://doi.org/10.1109/ICMAE.2017.8038683.

[10] R. Vos, R. Barrett, R. De Breuker, P. Tiso, Post-buckled precompressed elements: A new class of control actuators for morphing wing UAVs, Smart Mater. Struct. 16 (2007) 919-926. https://doi.org/10.1088/0964-1726/16/3/042. 
[11] R. Vos, R. De Breuker, R.M. Barrett, P. Tiso, Morphing Wing Flight Control Via Postbuckled Precompressed Piezoelectric Actuators, J. Aircr. 44 (2007) 1060-1068. https://doi.org/10.2514/1.21292.

[12] S.A. Tawfik, D. Stefan Dancila, E. Armanios, Unsymmetric composite laminates morphing via piezoelectric actuators, Compos. Part A Appl. Sci. Manuf. 42 (2011) 748-756. https://doi.org/10.1016/j.compositesa.2011.03.001.

[13] T. Lee, I. Chopra, Design of piezostack-driven trailing-edge flap actuator for helicopter rotors, Smart Mater. Struct. 10 (2001) 15-24. https://doi.org/10.1088/0964-1726/10/1/302.

[14] S.R. Hall, E.F. Prechtl, Development of a piezoelectric servoflap for helicopter rotor control, Smart Mater. Struct. 5 (1996) 26-34. https://doi.org/10.1088/0964-1726/5/1/004.

[15] S. Kota, R. Osborn, G. Ervin, D. Maric, P. Flick, D. Paul, Mission Adaptive Compliant Wing Design, Fabrication and Flight Test, in: RTO Appl. Veh. Technol. Panel Symp., 2009.

[16] A. Wissa, J. Calogero, N. Wereley, J.E. Hubbard, M. Frecker, Analytical model and stability analysis of the leading edge spar of a passively morphing ornithopter wing, Bioinspir. Biomim. 10 (2015) 065003. https://doi.org/10.1088/1748-3190/10/6/065003.

[17] S. Vasista, A. De Gaspari, S. Ricci, J. Riemenschneider, H.P. Monner, B. van de Kamp, Compliant structures-based wing and wingtip morphing devices, Aircr. Eng. Aerosp. Technol. 88 (2016) 311-330. https://doi.org/10.1108/AEAT-02-2015-0067.

[18] S. Vasista, J. Riemenschneider, H.P. Monner, Design and testing of a compliant mechanismbased demonstrator for a droop-nose morphing device, in: 23rd AIAA/AHS Adapt. Struct. Conf., 2015. https://doi.org/10.2514/6.2015-1049.

[19] R.M. Ajaj, M.I. Friswell, M. Bourchak, W. Harasani, Span morphing using the GNATSpar wing, Aerosp. Sci. Technol. 53 (2016) 38-46. https://doi.org/10.1016/j.ast.2016.03.009.

[20] S. Murugan, B.K.S. Woods, M.I. Friswell, Hierarchical modeling and optimization of camber morphing airfoil, Aerosp. Sci. Technol. $42 \quad$ (2015) 31-38. https://doi.org/10.1016/j.ast.2014.10.019.

[21] B.K.S. Woods, M.I. Friswell, The Adaptive Aspect Ratio morphing wing: Design concept and low fidelity skin optimization, Aerosp. Sci. Technol. 42 (2015) 209-217. https://doi.org/10.1016/j.ast.2015.01.012.

[22] W. Su, W. Song, A real-time hybrid aeroelastic simulation platform for flexible wings, Aerosp. Sci. Technol. 95 (2019) 105513. https://doi.org/10.1016/j.ast.2019.105513.

[23] X. Hang, W. Su, Q. Fei, D. Jiang, Analytical sensitivity analysis of flexible aircraft with the unsteady vortex-lattice aerodynamic theory, Aerosp. Sci. Technol. 99 (2020) 105612. https://doi.org/10.1016/j.ast.2019.105612.

[24] D. Tang, E.H. Dowell, Theoretical and Experimental Aeroelastic Study for Folding Wing Structures, J. Aircr. 45 (2008) 1136-1147. https://doi.org/10.2514/1.32754. 
[25] S. Liska, E.H. Dowell, Continuum Aeroelastic Model for a Folding-Wing Configuration, AIAA J. 47 (2009) 2350-2358. https://doi.org/10.2514/1.40475.

[26] P.J. Attar, D. Tang, E.H. Dowell, Nonlinear Aeroelastic Study for Folding Wing Structures, AIAA J. 48 (2010) 2187-2195. https://doi.org/10.2514/1.44868.

[27] S. Lee, T. Tjahjowidodo, H. Lee, B. Lai, Investigation of a robust tendon-sheath mechanism for flexible membrane wing application in mini-UAV, Mech. Syst. Signal Process. 85 (2017) 252266. https://doi.org/10.1016/j.ymssp.2016.08.014.

[28] L. Huang, Flutter of Cantilevered Plates in Axial Flow, J. Fluids Struct. 9 (1995) 127-147. https://doi.org/10.1006/jfls.1995.1007.

[29] A. Deivasigamani, J.M. McCarthy, S. John, S. Watkins, P. Trivailo, F. Coman, Flutter of cantilevered interconnected beams with variable hinge positions, J. Fluids Struct. 38 (2013) $223-$ 237. https://doi.org/10.1016/j.jfluidstructs.2012.10.011.

[30] M. Berci, P.H. Gaskell, R.W. Hewson, V. V. Toropov, A semi-analytical model for the combined aeroelastic behaviour and gust response of a flexible aerofoil, J. Fluids Struct. 38 (2013) 3-21. https://doi.org/10.1016/j.jfluidstructs.2012.11.004.

[31] J. Murua, R. Palacios, J. Peiró, Camber effects in the dynamic aeroelasticity of compliant airfoils, J. Fluids Struct. 26 (2010) 527-543. https://doi.org/10.1016/j.jfluidstructs.2010.01.009.

[32] J.R. Cook, M.J. Smith, Stability of Aeroelastic Airfoils with Camber Flexibility, J. Aircr. 51 (2014) 2024-2027. https://doi.org/10.2514/1.C032955.

[33] L. Bergami, M. Gaunaa, Stability investigation of an airfoil section with active flap control, Wind Energy. 13 (2010) 151-166. https://doi.org/10.1002/we.354.

[34] B.K.S. Woods, I. Dayyani, M.I. Friswell, Fluid/Structure-Interaction Analysis of the Fish-BoneActive-Camber Morphing Concept, J. Aircr. $52 \quad$ (2015) 307-319. https://doi.org/10.2514/1.C032725.

[35] J. Zhang, A.D. Shaw, A. Mohammadreza, M.I. Friswell, B.K.S. Woods, Spiral Pulley Negative Stiffness Mechanism for Morphing Aircraft Actuation, in: Vol. 5B 42nd Mech. Robot. Conf., American Society of Mechanical Engineers, 2018: p. V05BT07A003. https://doi.org/10.1115/DETC2018-85640.

[36] M. Mesarič, F. Kosel, Unsteady airload of an airfoil with variable camber, Aerosp. Sci. Technol. 8 (2004) 167-174. https://doi.org/10.1016/j.ast.2003.10.007.

[37] P. Rojratsirikul, Z. Wang, I. Gursul, Unsteady fluid-structure interactions of membrane airfoils at low Reynolds numbers, Exp. Fluids. 46 (2009) 859-872. https://doi.org/10.1007/s00348-0090623-8.

[38] S. Buoso, R. Palacios, Electro-aeromechanical modelling of actuated membrane wings, J. Fluids Struct. 58 (2015) 188-202. https://doi.org/10.1016/j.jfluidstructs.2015.08.010. 
[39] B. Gjerek, R. Drazumeric, F. Kosel, Flutter behavior of a flexible airfoil: Multiparameter experimental study, Aerosp. Sci. Technol. $36 \quad$ (2014) 75-86. https://doi.org/10.1016/j.ast.2014.04.002.

[40] R. Drazumeric, B. Gjerek, F. Kosel, P. Marzocca, Aeroelastic characteristic of an airfoil containing laminated composite plate, in: 55th AIAA/ASMe/ASCE/AHS/SC Struct. Struct. Dyn. Mater. Conf., 2014. https://doi.org/10.2514/6.2014-1196.

[41] Y. Liu, S. Wu, K. Zhang, Z. Wu, Gravitational orbit-attitude coupling dynamics of a large solar $\begin{array}{lllllll}\text { power } & \text { satellite, } & \text { Aerosp. } & \text { Sci. Technol. } 62 \text { (2017) }\end{array}$ https://doi.org/10.1016/j.ast.2016.11.030.

[42] Y. Liu, S. Wu, K. Zhang, Z. Wu, Parametrical Excitation Model for Rigid-Flexible Coupling System of Solar Power Satellite, J. Guid. Control. Dyn. 40 (2017) 2674-2681. https://doi.org/10.2514/1.G002739.

[43] Y. Li, C. Wang, W. Huang, Dynamics analysis of planar rigid-flexible coupling deployable solar array system with multiple revolute clearance joints, Mech. Syst. Signal Process. 117 (2019) 188-209. https://doi.org/10.1016/j.ymssp.2018.07.037.

[44] D. Liang, Y. Song, T. Sun, X. Jin, Dynamic modeling and hierarchical compound control of a novel 2-DOF flexible parallel manipulator with multiple actuation modes, Mech. Syst. Signal Process. 103 (2018) 413-439. https://doi.org/10.1016/j.ymssp.2017.10.004.

[45] Wang, C., J. Zhang, A.D. Shaw, M. Amoozgar, B.K. Friswell, M. I., Woods, Integration of the Spiral Pulley Negative Stiffness Mechanism into the FishBAC Morphing Wing., in: 9th ECCOMAS Themat. Conf. Smart Struct. Mater. (SMART 2019), Paris, France, 2019.

[46] G.-A. Tang, B. Chen, J.-H. Liu, M.-Y. Zhang, Model Reduction for Dynamic Analysis to Rod Component with Frequency-Dependent Damping, AIAA J. 54 (2016) 2489-2498. https://doi.org/10.2514/1.J053419.

[47] J. Wright, J. Cooper, Introduction to Aircraft Aeroelasticity and Loads, 2007. https://doi.org/10.2514/4.479359.

[48] M. Argentina, L. Mahadevan, Fluid-flow-induced flutter of a flag, Proc. Natl. Acad. Sci. 102 (2005) 1829-1834. https://doi.org/10.1073/pnas.0408383102.

[49] D.M. Tang, H. Yamamoto, E. H. Dowell, Flutter and limit cycle oscillations of two-dimensional panels in three-dimensional axial flow, J. Fluids Struct. 17 (2003) 225-242. https://doi.org/10.1016/S0889-9746(02)00121-4.

[50] G. Dimitriadis, Introduction to Nonlinear Aeroelasticity, 2017. https://doi.org/10.1002/9781118756478.

[51] B.K. Woods, O. Bilgen, M.I. Friswell, Wind tunnel testing of the fish bone active camber morphing concept, J. Intell. Mater. Syst. Struct. 25 (2014) 772-785. https://doi.org/10.1177/1045389X14521700. 
[52] G. Dimitriadis, J. Li, Bifurcation Behavior of Airfoil Undergoing Stall Flutter Oscillations in Low-Speed Wind Tunnel, AIAA J. 47 (2009) 2577-2596. https://doi.org/10.2514/1.39571.

[53] J. Zhang, S.D. Alexander, M. Amoozgar, M.I. Friswell, B.K.S. Woods, Spiral Pulley Negative Stiffness Mechanism for Morphing Aircraft Actuation, in: ASME 2018 Int. Des. Eng. Tech. Conf. Comput. Inf. Eng. Conf., ASME, 2018: p. V05AT08A018. https://doi.org/68019.

[54] R.E. Mortensen, Nonlinear System Theory: The Volterra/Wiener Approach (Wilson J. Rugh), SIAM Rev. (1983). https://doi.org/10.1137/1025092.

\section{Appendix}

\section{Unsteady Aerodynamic Model}

By using the Laplace transformation, the aerodynamic lift and moment can be rewritten as

$$
\begin{aligned}
\left\{\begin{array}{c}
-\bar{L} \\
\bar{M}
\end{array}\right\}=\left[\omega^{2} \boldsymbol{M}_{a}\right. & \left.-i \omega \boldsymbol{C}_{a 0}-i \omega C(k) \boldsymbol{C}_{a}^{0}-C(k) \boldsymbol{K}_{a}^{0}\right] \overline{\boldsymbol{y}}(\omega) \\
& =\left[\omega^{2} \boldsymbol{M}_{a}-i \omega\left(\boldsymbol{C}_{a 0}+D \boldsymbol{C}_{a}^{0}\right)-\left(D-\sum_{p=1}^{n}\left(\frac{C_{p}}{A_{p}^{\prime}}\right)\right) \boldsymbol{K}_{a}^{0}\right. \\
& \left.-\left(\sum_{p=1}^{n} \frac{i \omega\left(C_{p} \boldsymbol{C}_{a}^{0}-\frac{C_{p}}{A_{p}^{\prime}} \boldsymbol{K}_{a}\right)}{i\left(\omega b / U_{\infty}\right)-A_{p}^{\prime}}\right)\right] \overline{\boldsymbol{y}}(\omega)
\end{aligned}
$$

Theodorsen's function can be evaluated in terms of Bessel functions of the first and second kind. Thus,

$$
C(k)=D+\sum_{p=1}^{n} \frac{C_{p}}{i k-A_{p}^{\prime}},(i=\sqrt{-1})
$$

where $k=\omega b / U_{\infty}$ is the reduced frequency [47]. For $n=2$, the rationalfit function in MATLAB was used to obtain $D=0.508, A_{1}^{\prime}=-0.376, A_{2}^{\prime}=-0.091, C_{1}=0.086, C_{2}=0.022$ and the fitted curve is shown in Fig. A1.

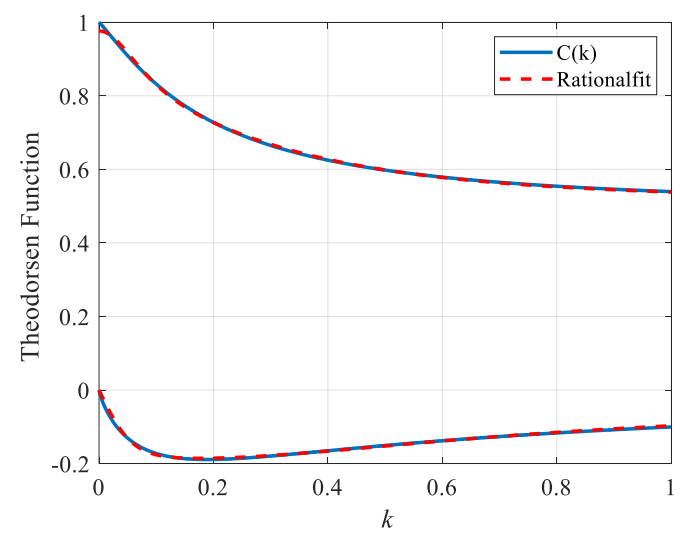


Figure A1. Theodorsen function and the fitted curve using 'rationalfit'.

Assuming $\boldsymbol{V}_{p}=\frac{U_{\infty} C_{p}}{b} \boldsymbol{C}_{a}^{0}+\frac{C_{p}}{A_{p}^{\prime}} \boldsymbol{K}_{a}, D_{p}=D-\sum_{p=1}^{n}\left(\frac{C_{p}}{A_{p}^{\prime}}\right), A_{P}=-A_{p}^{\prime} U_{\infty} / b, \boldsymbol{C}_{a}=\boldsymbol{C}_{a 0}+D \boldsymbol{C}_{a}^{0}$, then Eq. (A2) can be rewritten as

$$
\left\{\begin{array}{c}
-\bar{L} \\
\bar{M}
\end{array}\right\}=\left[\omega^{2} \boldsymbol{M}_{a}-i \omega \boldsymbol{C}_{a}-D_{p} \boldsymbol{K}_{a}-\left(\sum_{p=1}^{n} \frac{i \omega \boldsymbol{V}_{p}}{i \omega+A_{P}}\right)\right] \overline{\boldsymbol{y}}(\omega)
$$

According to Volterra theory [54], the first-order convolution is chosen to give the aerodynamic lift and moment as

$$
\left\{\begin{array}{c}
-\bar{M} \\
\bar{M}
\end{array}=-\boldsymbol{M}_{\boldsymbol{a}} \ddot{\boldsymbol{y}}(t)-\boldsymbol{C}_{a} \dot{\boldsymbol{y}}(t)-D_{p} \boldsymbol{K}_{a} \boldsymbol{y}(t)-\sum_{p=1}^{n}\left(\boldsymbol{V}_{\boldsymbol{p}} \int_{-\infty}^{t} e^{-A_{p}(t-\tau)} \dot{\boldsymbol{y}}(\tau) d \tau\right)\right.
$$

Recall the structural dynamics equations from Eq. (13) by adding the damping term as

$$
M_{s} \ddot{\xi}+C_{s} \dot{\xi}+K_{s} \xi=Q
$$

When $n=1$, the inertia force can be assumed as the external force according to d'Alembert's principle by combining Eqs. (3) and (4) as

$$
\boldsymbol{f}(t)=\boldsymbol{C} \dot{\boldsymbol{y}}+\boldsymbol{K} \boldsymbol{y}+\boldsymbol{V}_{1} \int_{-\infty}^{t} e^{-A_{1}(t-\tau)} \dot{\boldsymbol{y}}(\tau) d \tau
$$

where $\boldsymbol{C}=\boldsymbol{C}_{s}+\boldsymbol{C}_{a}$ and $\boldsymbol{K}=\boldsymbol{K}_{s}+D_{p} \boldsymbol{K}_{a}$.

The last term is the time-domain relationship expressed using the relaxation integral between the force $\boldsymbol{f}(t)$ and the displacement $\boldsymbol{y}(t)$ in one-dimensional problems [46]. According to Leibniz's Rule:

$$
\dot{\boldsymbol{f}}(t)=\boldsymbol{C} \ddot{\boldsymbol{y}}+\left(\boldsymbol{K}+\boldsymbol{V}_{1}\right) \dot{\boldsymbol{y}}-\left(\boldsymbol{V}_{1} A_{1} \int_{-\infty}^{t} e^{-A_{1}(t-\tau)} \dot{\boldsymbol{y}}(\tau) d \tau\right)
$$

Therefore, the singular value decomposition of $\boldsymbol{V}_{1}$ exists, and is a factorization of the form

$$
\boldsymbol{V}_{1}=U_{1} \Sigma_{1} U_{2}
$$

where $\boldsymbol{\Sigma}_{1}$ is a diagonal matrix with non-negative real numbers on the diagonal, $\boldsymbol{U}_{1}^{T} \boldsymbol{U}_{1}=\boldsymbol{I}$ and $\boldsymbol{U}_{2}^{T} \boldsymbol{U}_{2}=$ I.

Equation (A5a) is multiplied by $\frac{1}{A_{1}}$ and then added to Eq. (A5b) to give

$$
\boldsymbol{f}(t)+\frac{1}{A_{1}} \dot{\boldsymbol{f}}(t)=\frac{\boldsymbol{C}}{A_{1}} \ddot{\boldsymbol{y}}+\frac{1}{A_{1}}\left(\boldsymbol{K}+\boldsymbol{U}_{1} \boldsymbol{\Sigma}_{1} \boldsymbol{U}_{2}+A_{p} \boldsymbol{C}\right) \dot{\boldsymbol{y}}+\boldsymbol{K} \boldsymbol{y}
$$

Then, by employing additional DOFs, Eq. (A7) can be written as 


$$
\left[\begin{array}{ll}
\boldsymbol{C} & \mathbf{0} \\
\mathbf{0} & \boldsymbol{V}
\end{array}\right]\left\{\begin{array}{c}
\dot{\boldsymbol{y}} \\
\boldsymbol{i}
\end{array}\right\}+\left[\begin{array}{ll}
\boldsymbol{K}_{11} & \boldsymbol{K}_{12} \\
\boldsymbol{K}_{21} & \boldsymbol{K}_{22}
\end{array}\right]\left\{\begin{array}{l}
\boldsymbol{y} \\
\boldsymbol{v}
\end{array}\right\}=\left\{\begin{array}{l}
\boldsymbol{f} \\
\mathbf{0}
\end{array}\right\}
$$

where $\boldsymbol{v}$ is the vector of additional DOFs and $\boldsymbol{K}_{11} \in R^{N \times N}, \boldsymbol{K}_{12} \in R^{N \times N}, \boldsymbol{K}_{21} \in R^{N \times N}, \boldsymbol{K}_{22} \in R^{N \times N}$, $\boldsymbol{V} \in R^{N \times N}$ are all known matrices. Then

$$
\begin{gathered}
v=K_{12}{ }^{-1}\left(f-C \dot{y}-K_{11} y\right) \\
f+\left(K_{12} K_{22}{ }^{-1} V K_{12}{ }^{-1}\right) \dot{f} \\
=\left(K_{11}-K_{12} K_{22}^{-1} K_{21}\right) y+\left(K_{12} K_{22}{ }^{-1} V K_{12}{ }^{-1} K_{11}+C\right) \dot{y} \\
+\left(K_{12} K_{22}{ }^{-1} V K_{12}^{-1} C\right) \ddot{y}
\end{gathered}
$$

In order to be equivalent to Eq. (A7), three equations can be obtained

$$
\begin{gathered}
K_{12} K_{22}^{-1} V K_{12}^{-1}=\frac{1}{A_{1}} \\
K_{11}-K_{12} K_{22}{ }^{-1} K_{21}=K \\
K_{12} K_{22}{ }^{-1} V K_{12}{ }^{-1} K_{11}=\frac{1}{A_{1}}\left(K+U_{1} \Sigma_{1} U_{2}\right)
\end{gathered}
$$

Then,

$$
\begin{gathered}
\boldsymbol{K}_{22}=A_{1} \boldsymbol{V} \\
\boldsymbol{K}_{11}=\boldsymbol{K}+\boldsymbol{U}_{1} \boldsymbol{\Sigma}_{1} \boldsymbol{U}_{2} \\
\boldsymbol{K}_{12} \boldsymbol{V}^{-\mathbf{1}} \boldsymbol{K}_{21}=A_{1} \boldsymbol{U}_{1} \boldsymbol{\Sigma}_{1} \boldsymbol{U}_{2}
\end{gathered}
$$

Therefore, by using $\boldsymbol{V}=\boldsymbol{\Sigma}_{1}$

$$
\begin{gathered}
\boldsymbol{V}=\frac{1}{A_{1}} \boldsymbol{\Sigma}_{1} \\
\boldsymbol{K}_{\mathbf{1 2}} A_{1} \boldsymbol{\Sigma}_{\mathbf{1}} \boldsymbol{K}_{21}=A_{1} \boldsymbol{U}_{\mathbf{1}} \boldsymbol{\Sigma}_{\mathbf{1}} \boldsymbol{U}_{\mathbf{2}}
\end{gathered}
$$

Equation (A8) can be rewritten as

$$
\boldsymbol{C}_{\boldsymbol{t}} \dot{U}+\boldsymbol{K}_{\boldsymbol{t}} \boldsymbol{U}=\left\{\begin{array}{l}
\boldsymbol{f} \\
0
\end{array}\right\}
$$

where

$$
C_{t}=\left[\begin{array}{cc}
C & 0 \\
0 & \frac{1}{A_{1}} \Sigma_{1}
\end{array}\right], \quad K_{t}=\left[\begin{array}{cc}
K+U_{1} \Sigma_{1} U_{2} & U_{1} \Sigma_{1} \\
\Sigma_{1} U_{2} & \Sigma_{1}
\end{array}\right]
$$

Finally, by considering the first $n$ order of $\sum_{p=1}^{n}\left(\boldsymbol{V}_{\boldsymbol{p}} \int_{-\infty}^{t} e^{-A_{p}(t-\tau)} \dot{\boldsymbol{y}}(\tau) d \tau\right)$, the total equations 


$$
M_{t} \ddot{U}+C_{t} \dot{U}+K_{t} U=0
$$

where $\boldsymbol{M}_{\boldsymbol{t}}=\boldsymbol{d i a g}\left(\boldsymbol{M}_{S}+\boldsymbol{M}_{a} \quad 0 \quad \cdots \quad 0\right), \boldsymbol{C}_{\boldsymbol{t}}=\operatorname{diag}\left(\boldsymbol{C}_{s}+\boldsymbol{C}_{a} \quad \frac{1}{A_{1}} \boldsymbol{\Sigma}_{1} \quad \cdots \quad \frac{1}{A_{n}} \boldsymbol{\Sigma}_{n}\right)$ and $\boldsymbol{K}_{\boldsymbol{t}}=\left[\begin{array}{cccc}\boldsymbol{K}_{s}+D_{p} \boldsymbol{K}_{a}+\sum_{p=1}^{n} \boldsymbol{U}_{1 p} \boldsymbol{\Sigma}_{1} \boldsymbol{U}_{2 p} & \boldsymbol{U}_{1 \mathbf{1 1}} \boldsymbol{\Sigma}_{\mathbf{1}} & \cdots & \boldsymbol{U}_{1 n} \boldsymbol{\Sigma}_{\boldsymbol{n}} \\ \boldsymbol{\Sigma}_{\mathbf{1}} \boldsymbol{U}_{21} & \boldsymbol{\Sigma}_{1} & \cdots & 0 \\ \vdots & \vdots & \ddots & \vdots \\ \boldsymbol{\Sigma}_{n} \boldsymbol{U}_{2 n} & 0 & \cdots & \boldsymbol{\Sigma}_{n}\end{array}\right]$.

The singular value decomposition of $\boldsymbol{V}_{p}$ exists, and is a factorization of the form

$$
\boldsymbol{V}_{p}=\boldsymbol{U}_{1 p} \boldsymbol{\Sigma}_{p} \boldsymbol{U}_{2 p}
$$

where $\boldsymbol{\Sigma}_{p}$ is a diagonal matrix with non-negative real numbers on the diagonal, $\boldsymbol{U}_{1 p}^{\boldsymbol{T}} \boldsymbol{U}_{1 p}=\boldsymbol{I}$ and $\boldsymbol{U}_{2 p}^{\boldsymbol{T}} \boldsymbol{U}_{2 p}=\boldsymbol{I}$. 